\title{
Comparative study of liquid carbon dioxide and silver iodide seeding effects on cumulonimbus clouds rainfall enhancement and hail suppression
}

\author{
M. Najafi · S. Javanmard · F. Mohammad-Hosseinzadeh
}

Received: 22 July 2013/Revised: 1 July 2014/Accepted: 11 August 2014/Published online: 28 August 2014

(C) Islamic Azad University (IAU) 2014

\begin{abstract}
In this work, a comparative study of liquid carbon dioxide versus silver iodide seeding effects on a one-dimensional transient cumulonimbus cloud model is made. The over-riding concern is to figure out the implications of different seeding methods and agents for rainfall enhancement and hail suppression in cumulonimbus clouds. Based on the model results, it may be inferred that for the liquid carbon dioxide seeding, the seedability temperature limit is wider and the dynamic effects and precipitations are stronger compared to those of the silver iodide seeding. In addition, based on the model results, the rainfall enhancement can augment to $52 \%$ for liquid carbon dioxide as the cloud top level increases. However, this rainfall enhancement can augment to only $19 \%$ in the case of silver iodide seeding. Also, the model results show that for clouds with cloud top level less than $7 \mathrm{~km}$, the cumulative rainfall for the point seeding is less than that for the horizontal seeding, but for clouds with cloud top level more than $9 \mathrm{~km}$, the rainfall amount for the point seeding is more than that for the horizontal seeding. The results also show that there exist two threshold temperatures for the silver iodide seeding methods. The model results also indicate that the silver iodide seeding in the mixed clouds can be used for the cloud seeding with the aim of hail suppression. In general, the obtained results from this model show to be comparable with the recorded data at rain gauge stations.
\end{abstract}

M. Najafi $(\varangle) \cdot$ F. Mohammad-Hosseinzadeh Department of Mechanical and Aerospace Engineering, Science and Research Branch, Islamic Azad University, Tehran, Iran e-mail: M.njafi36@gmail.com

S. Javanmard

Atmospheric Science and Meteorological Research Center (ASMERC), Tehran, Iran
Keywords Homogenous and heterogeneous ice nucleation · Glaciogenic cloud seeding · Rainfall enhancement $\cdot$ Hail suppression

\section{Introduction}

Since cloud seeding operations are expensive, modeling a cloud for seeding to figure out feasibility of the seeding, forecasting, and evaluating the results of the seeding operations are very important. In a study carried out by Gharaylou et al. (2009), it was found that the rainfall modeling, microphysical, and dynamical processes, especially in cumulonimbus clouds are very determinative in small-scale modeling. Among numerical schemes, bulk microphysics parameterizations represent the particle size with a distribution function; thus, a limited number of parameters are required to describe the microphysical processes (Lin et al. 1983; Cotton et al. 1986; Tao and Simpson 1993; Reisner et al. 1998; Morrison et al. 2005). As a computational advantage, the bulk microphysics schemes are widely incorporated into the cloud-resolving models, mesoscale models, and climate models to simulate single clouds, mesoscale convective systems, and precipitation processes (Gao et al. 2011). In an another study, Golestani (2011) observed that precipitation of the convective clouds due to their high rainfall production during the year and the release of high amount of latent heat are of great importance and must be taken into account during the cloud seeding modeling.

In the cloud seeding operations, depending on the aim of the operation and conditions of cloud systems, suitable cloud seeding agents should be selected. Hence, correct selection of seeding agent is one of the most important factors to determine effective cloud seeding operation. 
Silver iodide and dry ice have been the most widely used in field projects and the most completely tested in laboratories. However, some aspects of their ice nucleation behavior as well as their effects on rainfall enhancement and hail suppression are still not completely known. Heterogeneous and homogeneous nucleation processes are two main known mechanisms for ice nucleation. The formerlike silver iodide (hereinafter shown as AgI) provides iceforming nuclei and the later acts as a coolant agent such as dry ice and liquified glaciogenics (such as propane, carbon dioxide, and nitrogen) generate ice crystals by intense cooling. Although the effectiveness of AgI depends on temperature, the number of generated ice crystals resulting from the coolant agents is nearly independent of temperature (Guo et al. 2006).

The ability to influence some clouds through the glaciogenic seeding is investigated by many investigators such as Braham (1986), Woodley et al. (1982), and Rosenfeld and Woodley (1989). Also, the effects of aerosols on microphysics, precipitation and dynamics of single clouds and cloud systems are investigated for conditions of high ( 4-4.3 km) freezing level by Levin and Cotton (2009), Rosenfeld et al. (2008), Khain (2009), and many others. The effects of aerosols on mid-latitude clouds and storms have been investigated to a less extent (Teller and Levin 2005, 2006). There are many field projects and numerical models which concentrate on some aspects of seeding materials and their effects on rainfall enhancement, hail suppression, and fog dissipation (e.g., English and Marwitz 1981; Fukuta 1996; Wakimizu et al. 2002; Xiao et al. 2005; Guo et al. 2006; Javanmard 1999; Javanmard et al. 2008; Karimpirhayati 2010; Seto et al. 2011; Zipori et al. 2012; Javanmard and Mohammad-Hosseinzadeh 2012). However, these studies concentrate on specific clouds or weather conditions. Schlesinger et al. (2006) carried out a three-dimensional cloud modeling study on the dynamical and microphysical variability of thunderstorms in different climate regimes. Seto et al. (2011) used a weather research forecasting model, radar and satellite data, and other equipment in a cloud seeding operation by liquid carbon dioxide (hereinafter shown as $\mathrm{LCO}_{2}$ ) in Japan in 2006. They studied the seeding effects on a stratus cloud having a 2-km thickness and a base height of 1,500 m. Orville et al. (1984, 1987), using a two-dimensional cloud model, simulated the seeding effects of stratiform-type clouds by AgI and dry ice. Guo et al. (2006) investigated the effects of the seeding by $\mathrm{AgI}$ and $\mathrm{LCO}_{2}$. The results of the latter work show that seeding by $\mathrm{LCO}_{2}$ and $\mathrm{AgI}$ at -15 to $-20{ }^{\circ} \mathrm{C}$ levels of clouds has almost the same dynamic effects on shallow convective clouds. However, seeding conducted by $\mathrm{LCO}_{2}$ in regions of maximum supercooled water having temperatures of 0 to $-5{ }^{\circ} \mathrm{C}$ produces much stronger dynamic effects and precipitation. Zhao and Lei (2010) used a three-dimensional mesoscale model, MM5, to investigate AgI seeding effects on accumulated rain on the ground surface for stratiform clouds. The model results indicated that the seeding may increase precipitation by $5-25 \%$ in the downwind area of the target location. In a work by Chen and Xiao (2010), their AgI seeding results indicated a substantial increase of ground surface accumulated precipitations of about $20-30 \%$.

In regard to glaciogenic seeding, most of the previous studies concentrated on a particular type of seeding agent, climate, region, time, and more often shallow convective and stratiform clouds. In addition, different seeding agents releasing methods and their effects on seeded convective clouds which have a mixed phase have been investigated to a less extent (e.g., Chen and Xiao 2010; Javanmard and Mohammad-Hosseinzadeh 2012). In spite of great progress in cloud seeding operations and numerical modelings (Orville 1996; Garstang et al. 2005), there are still many unknowns to be determined (Bruintjes 1999; Silverman 2001).

Based on the preceding literature search, the current work studies a cumulonimbus cloud model having two different cloud top levels (hereinafter shown as CTL) of 10.5 and $7 \mathrm{~km}$ which are seeded using a homogenous agent, $\mathrm{LCO}_{2}$, and a heterogeneous agent, AgI. Moreover, these seeding agents are released by two methods of point seeding (seeding a cloud at one point and only one time) and horizontal seeding (continuously seeding a cloud horizontally at one point, but several times during $30 \mathrm{~min}$ ). Sounding data of the present work are adjusted to produce clouds with different CTLs to investigate sensitivity of rainfall enhancement to different CTLs and seeding agents. This work uses a one-dimensional transient cumulonimbus cloud model with single-moment bulk parameterization (Javanmard and Mohammad-Hosseinzadeh 2012; Javanmard and Karimpirhayati 2012) to compare sensitivity of the seeding effects to CTLs, existence of mixed phase, and seeding methods for the two seeding agents of $\mathrm{LCO}_{2}$ and AgI. The work of this project was conducted at the department of mechanical and aerospace engineering in Tehran Science and Research branch of Islamic Azad University in Iran during 2011-2013.

\section{Materials and methods}

\section{Model descriptions}

In the present study, AgI is selected as a heterogeneous and $\mathrm{LCO}_{2}$ as a homogenous seeding agent. This selection is due to the fact that there exist some drawbacks concerning the other three common coolant seeding agents namely, liquefied propane (being flammable), liquefied nitrogen (not 
sprayable at its vapor pressure), and dry ice pellet (having rapid falling speed). In this work, the previous Najafi and Mohammad-Hosseinzadeh model (2013) is modified to simulate the cloud seeding operation scheme. Two releasing modes of the point and horizontal seeding methods are utilized in the current work. For the two releasing modes for both the two agents, the gamma distribution law is implemented to produce rain and ice species to predict the mixing ratios of cloud droplets, rain drops, cloud ice, snow, and hail-graupel. It should be noted here that, in the present model, the upper air data such as temperature, relative humidity, dew point temperature, and hydrostatic pressure are all functions of height or, in other words, the cloud is in a barotropic atmosphere. Moreover, the cloud is considered as a circular air column with a time-dependent radius in an environment at rest. It is assumed that the pressure adjusts itself instantaneously at any level to take the same value as that of the environment which is in hydrostatic equilibrium. The radius of the circular air column is assumed to be $3 \mathrm{~km}$.

In the earlier model by Najafi and Mohammad-Hosseinzadeh (2013), there have been two terms in their model energy equation (the last two terms) corresponding to the difference between the coolant seeding agent and the temperature of the cloud level being seeded. In that work, those temperatures were -90 and $-1{ }^{\circ} \mathrm{C}$, respectively. In the current work, however, the cloud level seeding temperature is changed to $-10{ }^{\circ} \mathrm{C}$ for the two point and horizontal seeding cases. At $-10{ }^{\circ} \mathrm{C}$, the number of generated ice crystals per gram of both the seeding agents is approximately equal to $10^{13}$ (Fukuta 1996). For the present work, the vertical spatial step is considered to be $250 \mathrm{~m}$, and the temporal step for the $\mathrm{LCO}_{2}$ seeding case is considered to be 1 versus $5 \mathrm{~s}$ for both the no-seeding and $\mathrm{AgI}$ seeding cases. Moreover, here, the clouds are seeded at the early mature stage (after $30 \mathrm{~min}$ from beginning of the cloud life cycle) and at a height of about $5.75 \mathrm{~km}$ above the ground surface having $-10^{\circ} \mathrm{C}$ temperatures. In the horizontal seeding case, the seeding time duration is considered to be $30 \mathrm{~min}$. The present model uses the same initial and boundary conditions as those of Karimpirhayati (2010). In order to produce two clouds, one with CTL of $10.5 \mathrm{~km}$ and the other with CTL of $7 \mathrm{~km}$ from $\mathrm{z} \mathrm{km}$ height above the ground surface onwards, the temperature of the sounding data is kept to be the same as the temperature of that height and kept constant. This process is continued until the ascending air column reaches a stable temperature layer where the cloud extension is suppressed. It needs to be mentioned here that when $z=10 \mathrm{~km}$, a mixed cloud with a CTL of $10.5 \mathrm{~km}$ is produced and when $z=5 \mathrm{~km}$, a cloud with a CTL of $7 \mathrm{~km}$ is formed. For the current model, the motion of the atmosphere of the environment is initiated by introducing a small updraft that has the form,
$w_{t=0}=\Delta w\left(z / z_{0}\right)\left(2-\left(z / z_{0}\right)\right)$,

which is appropriate for heights of less than $2 \mathrm{~km}$. In Eq. 1, $z$ denotes elevation from the ground, $\Delta w=1 \mathrm{~m} / \mathrm{s}$, and $z_{0}=1 \mathrm{~km}$ (Ogura and Takahashi 1971; Chen and Sun 2002).

\section{Model governing equations}

The dynamical and microphysical equations for the present model follow those of the Najafi and Mohammad-Hosseinzadeh (2013) model. The appropriate mass, momentum, and energy conservation equations which are used for all the hydrometeors considered in this model are as follows:

$$
\begin{aligned}
\frac{1}{r} \frac{\partial}{\partial r}( & \left.\rho_{a 0} r u\right)+\frac{\partial}{\partial z}\left(\rho_{a 0} w\right)=0 \\
\frac{\partial W}{\partial t}= & -w \frac{\partial w}{\partial z}-\frac{2\left(\alpha^{2}\right)}{a} w|w|+\frac{2}{a} \tilde{u}_{a}\left(w-\tilde{w}_{a}\right)+g \frac{T_{v}-T_{v 0}}{T_{v 0}} \\
& -g\left(Q_{\mathrm{CL}}+Q_{\mathrm{CI}}+Q_{\mathrm{R}}+Q_{\mathrm{S}}+Q_{\mathrm{G}}+X_{\mathrm{S}}\right), \text { and } \\
\frac{\partial T}{\partial t}= & -w\left(\frac{\partial T}{\partial z}-\Gamma_{d}\right)+\frac{2 \alpha^{2}}{a}|w|\left(T_{0}-T\right)+\frac{2}{a} \tilde{u}_{a}\left(T-\tilde{T}_{a}\right) \\
& +\left(\frac{L_{v}}{C_{P}}\right)\left(P_{\mathrm{COND}}-P_{\mathrm{CLEVP}}-P_{\mathrm{REVP}}\right) \\
& +\left(\frac{L_{\mathrm{S}}}{C_{\mathrm{P}}}\right)\left(-P_{\mathrm{IEVP}}+P_{\mathrm{NUA}}+P_{\mathrm{IDEP}}-P_{\mathrm{SSUB}}-P_{\mathrm{GSUB}}+P_{\mathrm{SDEP}}\right) \\
& +\left(\frac{L_{\mathrm{f}}}{C_{\mathrm{P}}}\right)\left(-P_{\mathrm{IMLT}}+P_{\mathrm{SFW}}+P_{\mathrm{IACRS}}+P_{\mathrm{SACRS}}+P_{\mathrm{SACW}}\right. \\
& -P_{\mathrm{SMLT}}+P_{\mathrm{GFR}}+P_{\mathrm{GACW}}+P_{\mathrm{GACR}}+P_{\mathrm{SACRG}}+P_{\mathrm{IACRG}} \\
& \left.-P_{\mathrm{GMLT}}+P_{\mathrm{NUH}}+P_{\mathrm{NUF}}+P_{\mathrm{ISR}}+P_{\mathrm{CSWC}}+P_{\mathrm{CSWD}}\right) \\
& -\frac{\partial X_{\mathrm{S}}}{\partial t}\left(T-T_{\mathrm{SLCO}}\right)-\frac{L_{\mathrm{LCO}}}{c_{\mathrm{P}}} \frac{\partial X_{\mathrm{s}}}{\partial t} .
\end{aligned}
$$

It should be noted here that the last two terms of the energy equation (Eq. 4) are used just for the $\mathrm{LCO}_{2}$ seeding case. Also, the conservation equations of the precipitating and non-precipitating hydrometeors mixing ratios and the seeding agent mixing ratio become, respectively

$$
\begin{aligned}
\frac{\partial Q_{j}}{\partial t}= & -\left(w-V_{j}\right) \frac{\partial Q_{j}}{\partial z}+\frac{2 \alpha^{2}}{a}|w|\left(Q_{j 0}-Q_{j}\right) \\
& +\frac{2}{a} \tilde{u}_{a}\left(Q_{j}-\tilde{Q}_{j a}\right)+Q_{j} \frac{\partial\left(\rho_{a 0} V_{j}\right)}{\rho_{a 0} \partial z}+\text { sources }- \text { sinks } \\
\frac{\partial Q_{y}}{\partial t}= & -w \frac{\partial Q_{y}}{\partial z}+\frac{2 \alpha^{2}}{a}|w|\left(Q_{y 0}-Q_{y}\right)+\frac{2}{a} \tilde{u}_{a}\left(Q_{y}-\tilde{Q}_{y a}\right) \\
& + \text { sources }- \text { sinks, and } \\
\frac{\partial X_{\mathrm{s}}}{\partial t}= & -w \frac{\partial X_{\mathrm{s}}}{\partial Z}-\frac{2 \alpha^{2}}{a}|w|\left(X_{\mathrm{s}}\right)+\frac{2}{a} \tilde{u}_{a}\left(X_{\mathrm{s}}-\tilde{X}_{\mathrm{s}}\right)+\operatorname{sinks}
\end{aligned}
$$


Where the subscripts " 0 " and " $a$ " denote the appropriate environmental and air column radius quantities, respectively. Also, $\rho, u, w, X_{s}, \tilde{u}_{a}$, and $\alpha^{2}$ are air density, radial, and vertical velocities, the seeding agent mixing ratio, entrainment or detrainment velocity, and lateral perturbation (which is considered equal to 0.1), respectively. Also, the superscript " " represents the lateral boundary values of the respective cloud (Chen and Sun 2002).

In the momentum equation (Eq. 3), the first term on the right represents the vertical advection, the second term, the lateral eddy exchange, the third term, the dynamic entrainment that is required to satisfy the mass continuity between the cloud and environment, the fourth term, the buoyancy, and the last term, the drag force that is assumed to be provided by the weight of the cloud droplets, cloud ice, rainwater, snow, hail-graupel, and seeding agent.

In the energy equation (Eq. 4 ), $\Gamma_{\mathrm{d}}, L_{\mathrm{v}}, L_{\mathrm{s}}, L_{\mathrm{f}}$, and $c_{\mathrm{p}}$ are the dry adiabatic lapse rate, latent heat of evaporation (600 cal/g), sublimation $(680 \mathrm{cal} / \mathrm{g})$, fusion $(80 \mathrm{cal} / \mathrm{g})$, and heat capacity at constant pressure for dry air $(1,000 \mathrm{~J} /$ $\mathrm{kg} \mathrm{K}$ ), respectively. Moreover, in this equation, the vaporization latent heat and the surface temperature of the seeding agent are $L_{\mathrm{LCO}_{2}}=55 \mathrm{cal} / \mathrm{g}$ and $T_{\mathrm{sLCO}_{2}}=-90^{\circ} \mathrm{C}$, respectively. Note that in Eq. $4, P$ denotes microphysical processes. This work contains 42 microphysical processes the same as those of Javanmard and Karimpirhayati (2012). For more details refer to Section D in the Appendix.

In the energy equation (Eq. 4), the first three terms have similar meaning as those of Eq. 3. In this equation, the last two terms represent the cooling process via heat conduction between the seeded air and $\mathrm{LCO}_{2}$ droplets, and the cooling process due to vaporization of $\mathrm{LCO}_{2}$, respectively. In Eq. 4, apart from the first three and the last two terms, the rest of the terms correspond to heating processes. These processes are due to condensation, or evaporation, deposition or sublimation, and accretion or fusion of particles.

In Eq. 5, $j=\mathrm{R}, \mathrm{S}$, and $\mathrm{G}$, where $\mathrm{R}$ denotes rain, $\mathrm{S}$ denotes snow, and $\mathrm{G}$ denotes graupel which are precipitating particles. In Eq. 6, $y=\mathrm{CI}$ and $\mathrm{CL}$, where $\mathrm{CI}$ denotes cloud ice and CL denotes cloud water which are non-precipitating particles. In Eqs. 5, 6, and 7, the first term on the right represents vertical advection, the second term, lateral eddy exchange, and the third term, in those equations represents dynamic entrainment of the precipitating particles, of the non-precipitating particles, and of the seeding agents, respectively. Also, the fourth term in Eq. 5 corresponds to terminal velocity of the precipitating particles.

The microphysical and dynamical processes calculations include the following judgments:

If $T \leq 273 \mathrm{~K}: Q_{\mathrm{V}}<Q_{\mathrm{IS}}$ or $Q_{\mathrm{V}}>Q_{\mathrm{VS}}$ or $Q_{\mathrm{IS}}<Q_{\mathrm{V}}<Q_{\mathrm{VS}}$, and If $T>273 \mathrm{~K}: Q_{\mathrm{V}}>Q_{\mathrm{VS}}$ or $Q_{\mathrm{V}}<Q_{\mathrm{Vs}}$.
In the above judgments, $Q_{\mathrm{IS}}$ and $Q_{\mathrm{vs}}$ denote saturation mixing ratios over ice and over water, respectively (Hsie et al. 1980; Guo et al. 2006; Javanmard and Jamali 2004).

Microphysical seeding assumptions and processes

When the seeding agent particles are injected into the cloud, three terms corresponding to the microphysical process due to seeding namely, the transformation of rainwater to precipitating ice $\left(P_{\mathrm{ISR}}\right)$, transformation of cloud water to cloud ice due to the contact nucleation $\left(P_{\mathrm{CSWC}}\right)$, and the depositional nucleation due to the Bergeron-Findisen process $\left(P_{\mathrm{CSWD}}\right)$ are added to the cloud processes. These terms are calculated through the following relations:

$P_{\mathrm{ISR}}=Q_{\mathrm{R}} \frac{N_{\mathrm{aR}}(\Delta T)}{\Delta t N_{\mathrm{R}}}, \quad P_{\mathrm{CSWC}}=Q_{\mathrm{CL}} \frac{N_{\mathrm{aW}}(\Delta T)}{\Delta t N_{\mathrm{W}}}, \quad$ and

$P_{\mathrm{CSWD}}=N_{\mathrm{aD}}(\Delta T) A^{\prime} m_{\mathrm{S}}^{B^{\prime}}$,

where the fraction of the seeding agent activated for the supercooling of $\Delta T$ for rainwater is $N_{\mathrm{aR}}(\Delta T)$ and that for cloud water is $N_{\mathrm{aw}}(\Delta T)$, the total number of rainwater is $N_{\mathrm{R}}$, and that for the cloud water is $N_{\mathrm{W}}$. Also, $N_{\mathrm{aD}}(\Delta T)$ denotes the number of seeding agent particles active as deposition nuclei for supercooling of $\Delta T$, and $m_{\mathrm{S}}$ denotes the mass of the seeding agent. It should be mentioned that $A^{\prime}$ and $B^{\prime}$ are the Bigg's time-dependent freezing parameters. The seeding processes appropriate terms and assumptions are described in details in Hsie et al. (1980), Guo et al. (2006), Young (1974), and Chen and Orville (1977).

Since the two seeding agents of homogenous and heterogeneous have different mechanism of producing ice nuclei, their injection mixing ratios are selected in different ways and amounts. The former generates ice crystals by strong cooling (typically provided by liquid $\mathrm{CO}_{2}$ ) and the later by lowering the energy barrier of new phase formation using ice-forming nuclei such as silver iodide. However, the number of generated ice crystals per gram for both the seeding agents at $-10^{\circ} \mathrm{C}$ is approximately $10^{13}$ (Fukuta 1996; Garvey 1975).

It should be mentioned here that the necessary amount of the coolant seeding agent $\left(\mathrm{LCO}_{2}\right)$ is calculated the same way as that in Najafi and Mohammad-Hosseinzadeh (2013) work which is described in Section C in the Appendix. Also, in the current work, the injecting amount of AgI mixing ratio is taken to be $1.2 \times 10^{-4} \mathrm{gg}^{-1}$ which is the optimum amount as shown in Fig. 12 in the Appendix. 


\section{Results and discussion}

The results of the $\mathrm{LCO}_{2}$ and $\mathrm{AgI}$ seeding on two deep convective clouds for the considered model are analyzed and compared here. Five types of hydrometeors namely, cloud water, cloud ice, snow, hail-graupel, and rain, are considered in this work. The study discusses the most effective quantities relevant to precipitation such as mixing ratio of hail-graupel and cloud ice and rainfall amount for the three cases of no-seeding, point seeding, and horizontal seeding. Moreover, threshold temperatures in two releasing modes of the AgI seeding are determined and discussed. Also, the appropriate sounding data are adjusted to produce clouds with different CTLs (5, 6, 7, 8, 9, and $10.5 \mathrm{~km}$ ) for seeding. The effects of seeding on those clouds are analyzed. In addition, the effects of mixed phase and cloud top level on two seeded clouds of one with mixed phase and one without are considered and focused on in Sections A, $\mathrm{B}$, and $\mathrm{E}$ of the Appendix. It should be mentioned here that all the presented results here only hold for the model's conditions specified in this study.

\section{Cloud ice mixing ratio}

Figure 1 shows variations of cloud ice mixing ratio of two clouds versus height and time. In this model, depending on the upper air data, the top of the cloud can go upward until it arrives at a level in which ice crystals can be formed; consequently, a cumulonimbus cloud with mixed phase can be created (Figs. 5, 7 in the Appendix). Due to the lower equilibrium vapor pressure of ice as compared to that of liquid water, ice crystals in the mixed clouds grow at the expense of the cloud droplets (Bergeron-Findisen process, Pruppacher and Klett 1997). Since natural ice nuclei increase dramatically at $-10{ }^{\circ} \mathrm{C}$ or colder, cloud with CTL of $10.5 \mathrm{~km}$ includes the mixed phase. As Fig. 2 indicates, in the cloud with CTL of $7 \mathrm{~km}$, cloud top does not reach high altitudes. In this cloud, the amount of ice formation is negligible. In general, most of the water found in these clouds is either partially or completely above the freezing level and exists in a metastable, or supercooled state. Understanding how ice is formed in these clouds is a major challenge in the science of cloud physics (Pruppacher and Klett 1997; khain et al. 2000). Freezing of pure water drops occurs spontaneously if temperature is low enough (homogeneous nucleation). If ice formation takes place by another substance (heterogeneous nucleation), the freezing processes initiates at higher temperatures (Rogers and Yau 1989; Pruppacher and Klett 1997). As the figure shows, in general, cloud ice is located in the updraft core in all the cases. The largest mixing ratios are located at and just above the updraft maximum (Figs. 1, 2). In the mixed cloud, the core of the cloud ice is located somewhere in between 8 and $10 \mathrm{~km}$ distance of the cloud. The cloud ice grows within this distance, mainly, by vapor deposition. Another point which can be observed from Fig. 1 is that, in the horizontal seeding cases of the mixed cloud, the generated cloud ice is concentrated in two cores, one above the freezing and seeding levels and the other one somewhere between 8 and $10 \mathrm{~km}$ distance where the cloud ice is produced naturally (Fig. 1). Moreover, based on this figure, the maximum amount of the cloud ice mixing ratio in the seeding cases is at least three times greater than that in the no-seeding cases. In addition, in the point seeding, the maximum amount of the ice mixing ratio in the $\mathrm{AgI}$ seeding is more than that in the $\mathrm{LCO}_{2}$ seeding for all the cases considered. These maximum levels are all highlighted in the figure. It is noted, however, that for the mixed cloud in the horizontal seeding case the situation is reversed (Fig. 1).

\section{Comparison of hydrometeor mixing ratios}

Figure 2 shows variations of total mixing ratios of different hydrometeors versus time for the no-seeding cases point and horizontal seeding cases using $\mathrm{AgI}$ and $\mathrm{LCO}_{2}$ for the clouds with mixed phase. In this figure, each point on the curve at each time represents the sum of all the values of that mixing ratio at different heights from the ground level to the top of the cloud. These curves are labeled with "QXT," as Q denotes mixing ratio, T denotes total amount, and $X$ can take either one of $\mathrm{G}, \mathrm{R}, \mathrm{CL}, \mathrm{S}$, and $\mathrm{CI}$ as ordered in the figure. It is noticed here that the total amount of the produced hail-graupel mixing ratio is increased for the $\mathrm{LCO}_{2}$, but it is decreased for the AgI seeding cases. As Fig. 2 shows, AgI seeding increases snow and cloud ice mixing ratios and decreases hail-graupel mixing ratio. Also, horizontal seeding for $\mathrm{AgI}$ injection resulted in a noticeable increase of snow and cloud ice mixing ratio. In this case, the cloud water mixing ratio is decreased. It seems that, in the AgI seeding, due to the competition process and shortage of cloud water, the generated ice crystals do not have enough opportunity to grow and produce hail-graupel (khain et al. 2011). For the $\mathrm{LCO}_{2}$ seeding, cloud ice, snow, and graupel mixing ratios are increased, significantly. Also, in the $\mathrm{LCO}_{2}$ seeding case, the increase of graupel mixing ratio in the point seeding mode is more than that in the horizontal seeding. Based on the model calculations, the maximum hail-graupel production and rainfall intensity take place at the same time. This is verified in Franklin et al. (2005) work (see the Appendix for more details).

Ice-phase processes play a primary role in initiation and production of precipitation in convective clouds (Johnson et al. 1993, 1994). The latent heat released from freezing of 
(a) Cloud ice mixing ratio(g/kg)

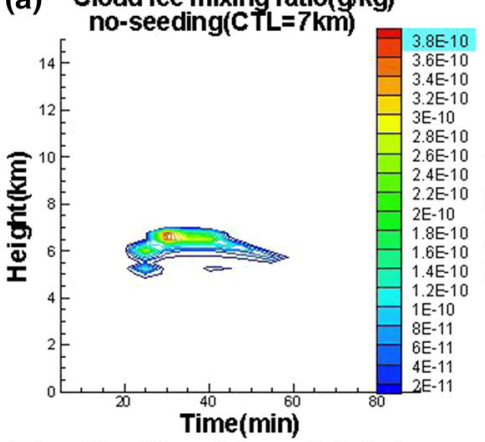

(b) Cloud ice mixing ratio $(\mathrm{g} / \mathrm{kg})$

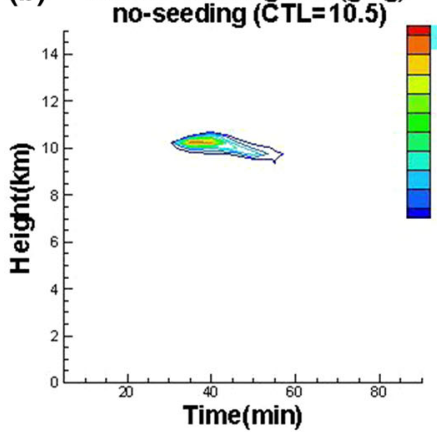

(a) Cloud ice mixing ratio( $(\mathrm{g} / \mathrm{kg})$

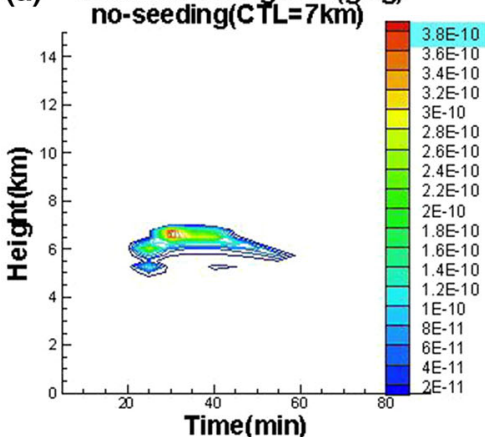

(b) Cloud ice mixing ratio $(\mathrm{g} / \mathrm{kg}$ )

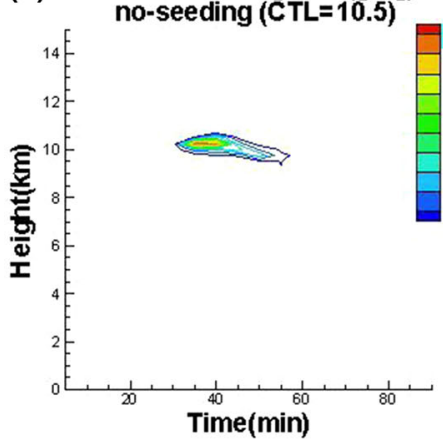

(a) Cloud ice mixing ratio $(\mathrm{g} / \mathrm{kg})$
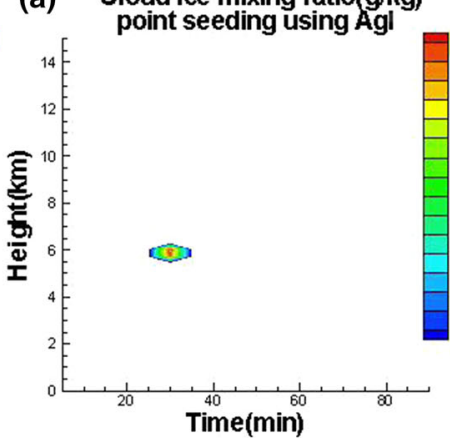

(b) Cloud ice mixing ratio $(\mathrm{g} / \mathrm{kg})$

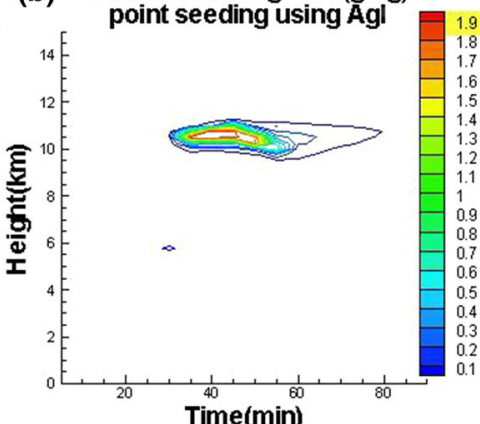

(a) Cloud ice mixing ratio( $/ \mathrm{g} / \mathrm{kg})$

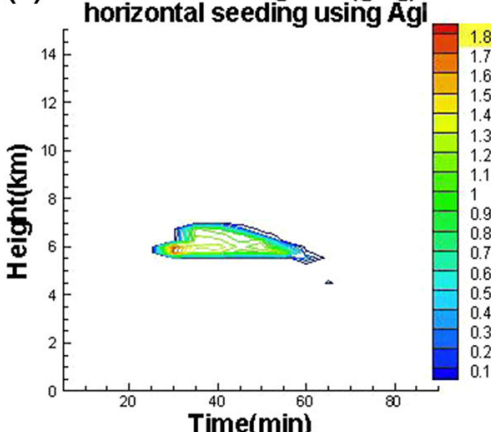

(b) Cloud ice mixing ratio $(\mathrm{g} / \mathrm{kg})$

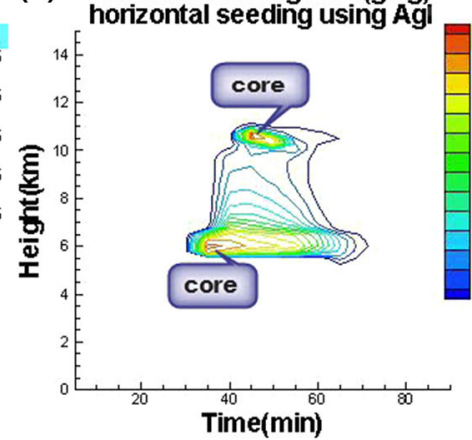

(a) Cloud ice mixing ratio(g/kg)
point seeding using LCo2

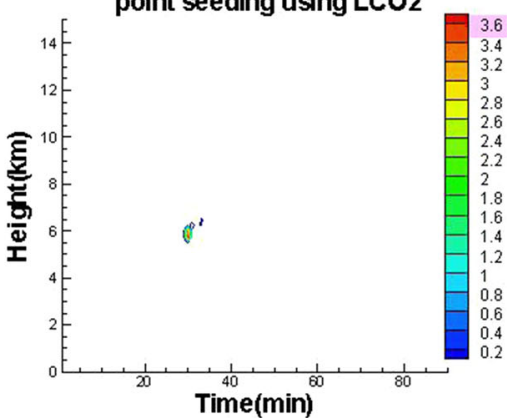

(b) Cloud ice mixing ratio(g/kg)

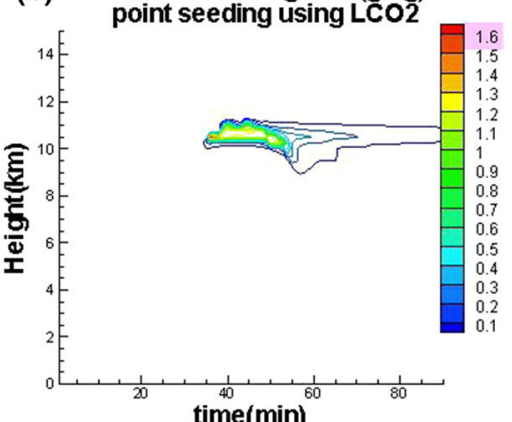

(a) Cloud ice mixing ratio(g/kg)

horizontal seeding using $\mathrm{LCO} 2$

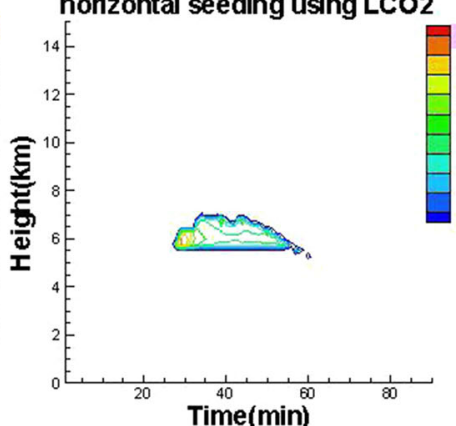

(b) Cloud ice mixing ratio $(\mathrm{g} / \mathrm{kg})$

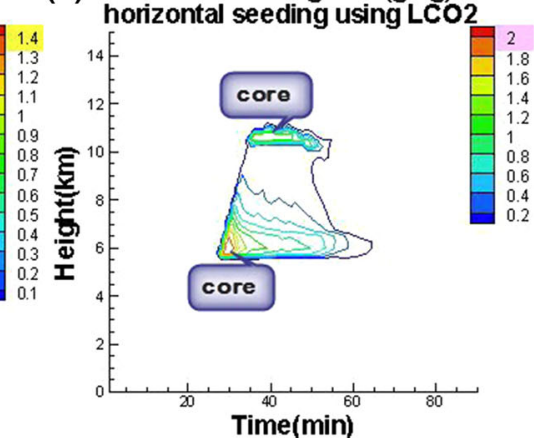

Fig. 1 Cloud ice mixing ratio

water drops and deposition of water vapor on ice particles result in producing a much warmer cloud which, in turn, enhances growth of the cloud. This means that in the mixed cloud, due to the seeding, a height increase can be observed as shown in Fig. 2 (also see Fig. 5 in Section E of the Appendix). It is noted here that in the point seeding mode of the AgI seeding, snow is produced approximately
10 min earlier compared to that in the horizontal seeding. This phenomenon may cause less amount of maximum graupel mixing ratio and more amount of rainfall enhancement in the point seeding compared to that in the horizontal seeding. Although in the horizontal seeding by $\mathrm{LCO}_{2}$ the amounts of snow and ice formed are augmented, the results, however, show that the cooling effect (by 
(a) no-seeding ( $\mathrm{CTL}=10.5 \mathrm{~km})$

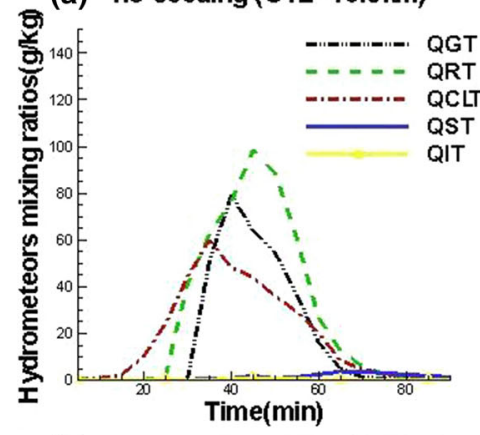

(b) no-seeding (CTL=10.5 km)

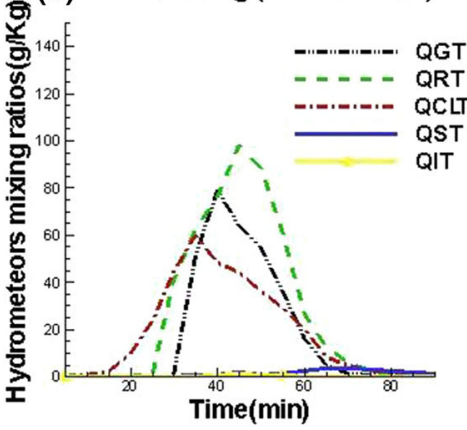

(a) point seeding using Agl

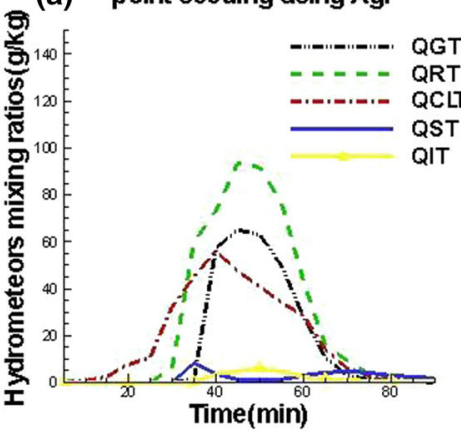

(b) point seeding using $\mathrm{LCO} 2$

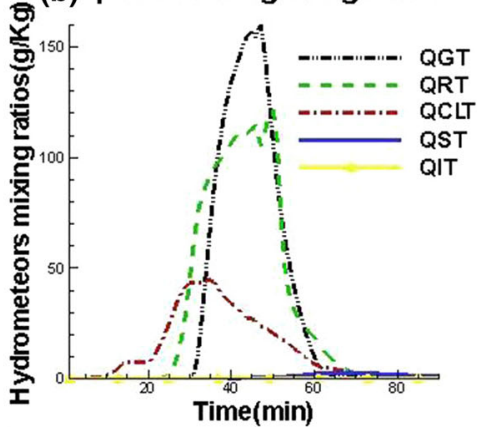

(a) horizontal seeding using Agl

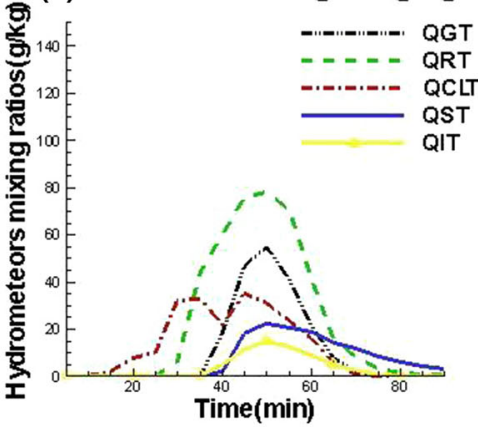

(b) horizontal seeding using $\mathrm{LCO} 2$

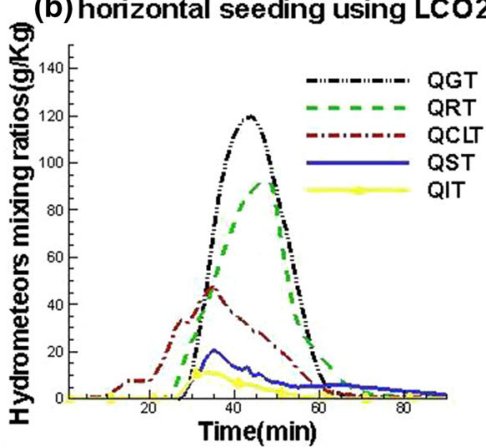

Fig. 2 Hydrometeors mixing ratios versus time

Table 1 Maximum amount of hail-graupel mixing ratio $(\mathrm{g} / \mathrm{kg})$

\begin{tabular}{|c|c|c|c|c|c|}
\hline $\begin{array}{l}\text { CTL } \\
(\mathrm{km})\end{array}$ & $\begin{array}{l}\text { No- } \\
\text { seeding }\end{array}$ & $\begin{array}{l}\text { AgI- } \\
\text { point } \\
\text { seeding }\end{array}$ & $\begin{array}{l}\mathrm{LCO}_{2-} \\
\text { point } \\
\text { seeding }\end{array}$ & $\begin{array}{l}\text { AgI- } \\
\text { horizontal } \\
\text { seeding }\end{array}$ & $\begin{array}{l}\mathrm{LCO}_{2^{-}} \\
\text {horizontal } \\
\text { seeding }\end{array}$ \\
\hline 7 & 4 & 2.8 & 5.5 & 6 & 6 \\
\hline 10.5 & 7 & 3.2 & 7.5 & 3.4 & 7 \\
\hline
\end{tabular}

$\mathrm{LCO}_{2}$ ) on the latent heat released (due to the ice processes) takes over causing a hail increase in the cloud.

\section{Graupel mixing ratio}

Table 1 shows the maximum amount of hail-graupel mixing ratio for different seeding modes, seeding agents, and CTLs (see Fig. 9 in Section E of the Appendix). The results of the model show that the amount of graupel mixing ratio is sensitive to CTL, mixed phase of clouds, and releasing methods of seeding agents. It can be seen from the table that, in the cloud with mixed phase in the point seeding, the decrease of the maximum graupel mixing ratio is more than that in the cloud with mixed phase in the horizontal seeding. As the table shows, the AgI cloud seeding can decrease the maximum amount of the graupel mixing ratio in the mixed cloud significantly. However, the $\mathrm{LCO}_{2}$ seeding of the cloud without mixed phase increases the maximum amount of the graupel mixing ratio. It is noted here that although AgI injection into the cloud without the mixed phase $(\mathrm{CTL}=7 \mathrm{~km})$ in the point releasing mode can decrease the maximum amount of the graupel mixing ratio, in the horizontal releasing mode, however, the injection may increase the ratio. On the contrary, as the table indicates, $\mathrm{LCO}_{2}$ seeding does not show any noticeable effects on the mixed cloud.

Based on the obtained model results for the mixed clouds, extension of regions with positive value of $S_{\mathrm{i}}$ (supersaturation with respect to ice) in the AgI seeded cloud is less than that in the no-seeding and in the $\mathrm{LCO}_{2}$ seeding cases (see red circles in Fig. 6 of Section E of the Appendix). Therefore, the hail-graupel growth due to the AgI seeding is less than that in other cases. It can be inferred that in the AgI seeding case, the seeding increases the ice embryos concentration significantly so that the artificial and natural ice particles compete with one another to consume more of the available liquid water. The supercooled water is now redistributed among all the ice embryos; hence, small hailstones are formed. Falling to the ground, they melt to rain or snow, and in the other word, "beneficial competition" phenomenon may have taken place here. Hence, AgI seeding in the mixed cloud can be used for the cloud seeding with the aim of hail suppression (Figs. 1, 2, 9, Table 1). It should be noted here that our model is a single-moment bulk model and cannot predict the number density of water species added to the mixing ratios. Obviously, if it were a double-moment bulk model, 
explaining hail suppression and beneficial competition for seeding agents would have been easy and would have been based on the number density of ice crystals (Lim and Hong 2010; Lee and Donner 2011). In this present work, $\mathrm{LCO}_{2}$ seeding does not decrease the amount of hail/graupel mixing ratio, but in other situations (e.g., Javanmard and Mohammad-Hosseinzadeh 2012), it may cause hail suppression.

Based on the results obtained from the model (Fig. 9 in the Appendix), the maximum amount of the hail-graupel mixing ratio is observed to take place within the core of a thunderstorm. This coincides with the results of Rui et al. (2010).

Cloud seeding effects on cumulative rainfall enhancement

Figure 3 shows variations of cumulative rainfall for different CTLs for both $\mathrm{LCO}_{2}$ and $\mathrm{AgI}$ seeding agents for all the cases considered. As the figure shows, the cumulative rainfall amount is sensitive to the seeding agents, methods (different releasing modes of seeding agent), and CTL of clouds. Based on this figure, for clouds with CTL less than $7 \mathrm{~km}$, the cumulative rainfall from the point seeding is less than that from the horizontal seeding. However, for clouds with the CTL more than $9 \mathrm{~km}$, the rainfall amount from the point seeding is more than that from the horizontal seeding. Moreover, based on the model results, for clouds with the CTL more than $9 \mathrm{~km}$, the $\mathrm{LCO}_{2}$ seeding shows to enhance the cumulative rainfall amount significantly compared to the AgI seeding. These results are in good agreement with those of Fukuta (1996) and Wakimizu et al. (2002). This observation shows that the releasing methods of the seeding agents are sensitive to CTLs. Thus, for achieving a high cumulative rainfall enhancement, the point and horizontal seeding methods should be selected appropriately. As Fig. 3 illustrates, the cumulative rainfall enhancement can change from 1 to $52 \%$ for $\mathrm{LCO}_{2}$ seeding cases and only to $19 \%$ for the AgI seeding. As this figure shows, the most amount of cumulative rainfall enhancement due to the AgI seeding takes place in the cloud with a CTL of $7 \mathrm{~km}$. This is due to the fact that the clouds with CTLs more than $7 \mathrm{~km}$ have mixed phase and those with CTLs less than $7 \mathrm{~km}$ have shortage of supercooled cloud water. For mixed clouds, since releasing $\mathrm{AgI}$ at $-10{ }^{\circ} \mathrm{C}$ temperature can cause a competition process, this may decrease the amount of the cumulative rainfall enhancement. In other words, injecting AgI into the cloud with a CTL less than $7 \mathrm{~km}$ or a cloud top temperature more than $-17{ }^{\circ} \mathrm{C}$ makes a small suitable window of temperature and time for ice nuclei growth. From another perspective, injecting AgI into a cloud with a CTL more than $7 \mathrm{~km}$ can cause a competition process due to the existence of mixed phase in the cloud

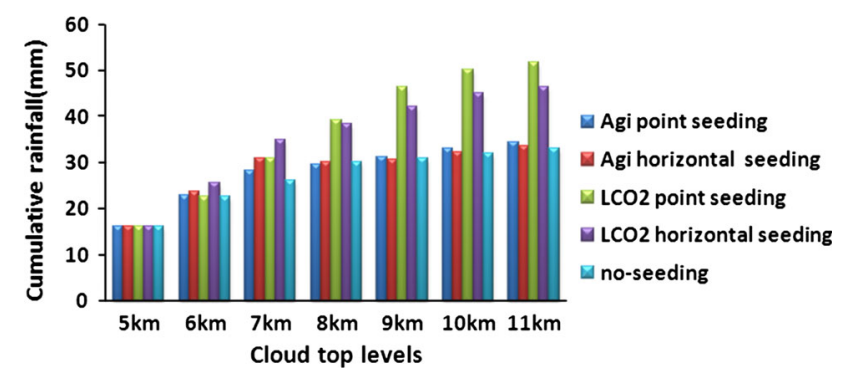

Fig. 3 Cumulative rainfall on ground versus CTLs

and as a result, overseeding may decrease the cumulative rainfall enhancement. It should be noted that there are some studies conducted on convective clouds which suggest that clouds with tops colder than about $-25^{\circ} \mathrm{C}$ have sufficiently large concentrations of natural ice crystals so that seeding has no effects on their precipitations (Conrad 2006). The results obtained in the present work, however, indicate that the forgoing statement is only true for the AgI and not for the $\mathrm{LCO}_{2}$ seeding. Hence, the cumulative rainfall enhancement due to the $\mathrm{LCO}_{2}$ seeding increases with increase of CTLs (Fig. 3). This indicates that the competition process is not effective on the results of the $\mathrm{LCO}_{2}$ seeding. As this figure shows, the cumulative rainfall amount of the clouds increases with the increase of their CTLs. In fact, since convective motions and heat transfer for these clouds increase (due to increase of the cloud thickness), the cumulative rainfall produced by the clouds with higher CTLs increases. Although these clouds droplets upward motions are very slow near the cloud base, the increase of the cloud thickness can augment the cloud instability due to release of the latent heat of cloud water and seeding agent. Therefore, with increase in cloud water heat transfer and the convective available potential energy (CAPE), consequently, the cumulative rainfall increases (Rogers and Yau 1989).

Coolant seeding agents (e.g., $\mathrm{LCO}_{2}$ ) release can produce abundant ice crystals at temperatures as warm as $-1{ }^{\circ} \mathrm{C}$ with little temperature dependency. However, the air temperature must be $-5{ }^{\circ} \mathrm{C}$ or colder for $\mathrm{AgI}$ to begin forming ice crystals by artificial nucleation of supercooled liquid water, or $-8{ }^{\circ} \mathrm{C}$ or colder to produce enough crystals to generate significant snowfall. The efficiency of the AgI seeding increases as the temperature decreases until a specific temperature is attained. After this "threshold temperature" (at which a small, but detectable fraction of a large population of $\mathrm{AgI}$ agents act as ice nuclei), further cooling of the supercooled liquid water cloud will result in many orders of magnitude higher effective AgI agents. Since natural ice nucleation dramatically increases at about $-10{ }^{\circ} \mathrm{C}$ or colder, there is a narrower temperature "window" (compared to that for $\mathrm{LCO}_{2}$ ) in which $\mathrm{AgI}$ can 
Fig. 4 Rainfall intensity on ground versus time

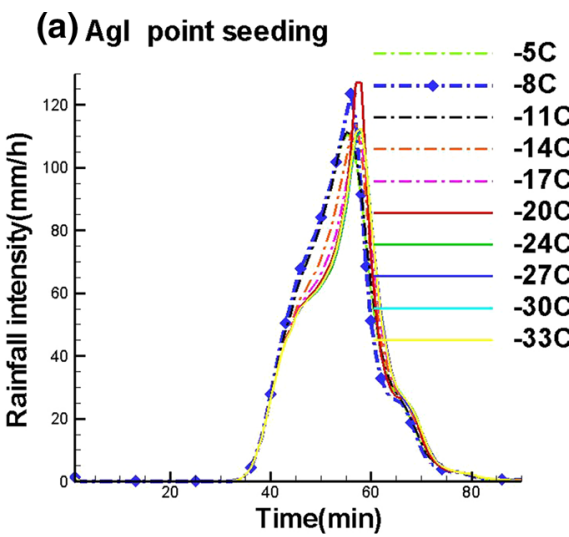

augment precipitation where nature cannot. This temperature window may reduce the time period for crystals to grow at the proper temperatures and suitable supercooled liquid water conditions (Zipori et al. 2012). It can be concluded here that the aforementioned phenomena cause lower cumulative rainfall enhancement for the $\mathrm{AgI}$ seeding compared to that for the $\mathrm{LCO}_{2}$ seeding as it can be seen in Fig. 3.

Rainfall intensity sensitivity of $\mathrm{AgI}$ seeding modes with respect to seeding temperature

Since the number of ice nuclei produced by $\mathrm{LCO}_{2}$ is almost temperature independent and its sensitivity to the seeding modes has been discussed in earlier works by the authors (Najafi and Mohammad-Hosseinzadeh 2013; Javanmard and Mohammad-Hosseinzadeh 2012), this section concentrates only on the sensitivity of rainfall intensity with respect to seeding temperature only for the AgI seeding modes. Figure 4 shows implications of the AgI seeding temperatures for the ground rainfall intensity of the mixed cloud versus time for the point and horizontal seeding cases. As this figure indicates, there are two threshold temperatures for each seeding method. As it is expected, one of these temperatures, for both seeding modes, is $-20{ }^{\circ} \mathrm{C}$ at which all the seeding agents become active as ice nuclei. The other temperature is $-8{ }^{\circ} \mathrm{C}$ for the point and $-11{ }^{\circ} \mathrm{C}$ for the horizontal seeding methods. These are the temperatures around which the maximum vapor pressure difference between the liquid water and ice occurs in the mixed cloud. These threshold temperatures are indicated by diamond symbol in this figure. As shown in Figs. 2 and 4, it seems that in the point seeding, since ice processes are initiated about 10 min earlier than that in the horizontal seeding, the second threshold temperature of the point seeding $\left(-8{ }^{\circ} \mathrm{C}\right)$ occurs at the warmer temperature compared to that $\left(-11^{\circ} \mathrm{C}\right)$ of the horizontal seeding (Bergeron-Findisen process).

\section{Conclusion}

Based on the model considered in this study, a comparative study of liquid $\mathrm{CO}_{2}$ versus $\mathrm{AgI}$ seeding effects on rainfall enhancement and hail suppression in cumulonimbus clouds is made. For injections, $\mathrm{AgI}$ is selected as a heterogeneous seeding agent and $\mathrm{LCO}_{2}$ as a homogenous one. A onedimensional time-dependent cloud model with bulk parameterization is used as an extension of Karimpirhayati's deep convective cloud model (2010). Two releasing modes of point and horizontal seeding are numerically simulated at $-10{ }^{\circ} \mathrm{C}$. At this temperature, the number of generated ice crystals per gram for both the seeding agents is approximately equal to $10^{13}$. For the two releasing modes, for the two agents, the gamma distribution law is implemented for the production of rain and ice species to predict the mixing ratios of cloud droplets, rain drops, cloud ice, snow, and hail-graupel. Appropriate sounding data are adjusted to produce clouds with CTLs of 5, 6, 7, 8, 9, and $10.5 \mathrm{~km}$. The $\mathrm{AgI}$ and $\mathrm{LCO}_{2}$ injections are conducted in cloud regions that contain high magnitude of upward motions and high amount of supercooled water.

Based on the model results, it may be inferred that the $\mathrm{LCO}_{2}$ seeding produces stronger dynamic effects and precipitation than the $\mathrm{AgI}$ seeding due to the formation of more new convective cells of the seeded cloud and a wider temperature window of seedability (Fig. 4). This phenomenon occurring in the region of the maximum supercooled water with temperature of 0 to $-5{ }^{\circ} \mathrm{C}$ is verified by Guo et al. (2006) work. The results obtained from the model show that the temporal extension and the maximum values of downward motions in the seeded cloud by $\mathrm{LCO}_{2}$ are more than those by AgI. In the $\mathrm{LCO}_{2}$ seeding, the vertical velocity reaches to its maximum in the developing stage with a steep slope, and the downward motions become stronger. In the AgI seeding cases, at each specific moment of the cloud life cycle, as the cloud altitude is increased, the vertical velocity is increased and decreased 
stochastically. It should be noted that there are some studies conducted on convective clouds which suggest that clouds with tops colder than about $-25^{\circ} \mathrm{C}$ have sufficiently large concentrations of natural ice crystals so that the seeding has negligible effects on their precipitations (Conrad 2006). The results obtained in this work, however, indicate that this statement is only true for the AgI and not for the $\mathrm{LCO}_{2}$ seeding.

The rainfall intensity obtained from the model shows to be comparable with the rainfall intensity data recorded at the rain gauges given in Morin et al. (2006) work (Fig. 4). The illustrated results show that there are two threshold temperatures for each seeding method. As it is expected, one of those temperatures for both seeding modes is $-20{ }^{\circ} \mathrm{C}$ at which all the seeding agents' particles become active as ice nuclei. The other temperatures are -8 and $-11^{\circ} \mathrm{C}$ for the point and horizontal seeding methods, respectively (Fig. 4). The current work shows that the rainfall and graupel mixing ratio are sensitive to the seeding agents, methods (different releasing methods of seeding agent), and CTLs. The depicted results show that for a cloud with a CTL less than $7 \mathrm{~km}$, the cumulative rainfall from the point seeding is less than that from the horizontal seeding, but for a cloud with a CTL more than $9 \mathrm{~km}$, the rainfall amount from the point seeding is more than that from the horizontal seeding. Moreover, based on the present model results, for clouds taller than $9 \mathrm{~km}$, the enhancement of cumulative rainfall amount through the AgI seeding is insignificant. However, for the same clouds, the cumulative rainfall amount enhancement through the $\mathrm{LCO}_{2}$ seeding is substantial. These results are in good agreement with those of Fukuta (1996) and Wakimizu et al. (2002). In fact, quantitatively, the current model illustrates a cumulative rainfall enhancement from 1 to $52 \%$ in $\mathrm{LCO}_{2}$ seeding versus to only $19 \%$ in AgI seeding. Since clouds with a CTL more than $7 \mathrm{~km}$ have a mixed phase and those with a CTL less than $7 \mathrm{~km}$ have a shortage of supercooled cloud water, the most amount of cumulative rainfall enhancement for the AgI seeding takes place in the cloud with CTL of $7 \mathrm{~km}$ as shown in Fig. 3. Moreover, the maximum amount of cumulative rainfall enhancement for AgI seeding in this study is comparable with those of Chen and Xiao (2010).

The results generated by the model show that injecting AgI into the cloud with CTLs less than $7 \mathrm{~km}$ or with cloud top temperatures more than $-17{ }^{\circ} \mathrm{C}$ makes a narrow and suitable window of temperature and time with insufficient amount of supercooled water for the ice nuclei to grow. This prevents the growth of initial hail embryos to become hail of stone size. This is in good agreement with hail suppression hypotheses stated by Krauss (1999), Heymsfield (1982), and others. Based on the results obtained, seeding by $\mathrm{LCO}_{2}$ like liquid propane may expand the temperature window of seedability (Griffith and Solak 2006). This expansion causes more rainfall and hail fall enhancement by $\mathrm{LCO}_{2}$ seeding than those by AgI seeding (Fig. 3). The results here also show that the hail-graupel growth, due to deposition of AgI seeding, is less than that in $\mathrm{LCO}_{2}$ seeding. In addition, the model results indicate that, for the AgI seeding, the total amount of snow and cloud ice mixing ratios are increased, but the total amount of hail-graupel mixing ratio is decreased. Therefore, it can be inferred that, in the AgI seeding case, the beneficial competition phenomenon may have taken place here, and as a result, the ice crystals did not have enough opportunity to grow and produce hail-graupel particles (Khain et al. 2011). Hence, AgI seeding in the mixed cloud can be used for cloud seeding with the aim of hail suppression (Figs. 1, 2, 9, Table 1). However, it should be noted here that $\mathrm{LCO}_{2}$ seeding in this present work does not decrease the amount of hail/graupel mixing ratio, but in other situations like in Javanmard and Mohammad-Hosseinzadeh (2012) case it may cause hail suppression.

It is important to mention here that care must, of course, be taken that the above analyses are just for the proposed model including its entire boundary and initial conditions. The analyses only represent the authors' point of views and can only be used as some guidance for further investigations in the field.

Acknowledgments The authors are very thankful to Atmospheric Science and Meteorological Research Center (ASMERC) for their technical support in this study and also to M. Karimpirhayati for her great work.

\section{Appendix}

Section A: Cloud formation

Assuming that water vapor mixing ratio in air is $Q_{\mathrm{v}}$, then supersaturation with respect to water $(S)$ and with respect to ice $\left(S_{\mathrm{i}}\right)$ is calculated as (Karimpirhayati 2010),

$S=\frac{Q_{\mathrm{v}}}{Q_{\mathrm{vs}}}-1 \quad$ and $\quad S_{i}=\frac{Q_{\mathrm{v}}}{Q_{\mathrm{is}}}-1$,

where $Q_{\mathrm{vs}}$ and $Q_{\mathrm{is}}$ are saturation mixing ratio over water and ice, respectively. Moreover, these two terms are functions of pressure $(P)$ and temperature $(T)$ and they are calculated as follows:

$Q_{\mathrm{iS}}=3.8 P^{-1} 10^{\frac{9.5(T-273)}{T-8}}, \quad Q_{\mathrm{VS}}=3.8 P^{-1} 10^{\frac{7.5(T-273)}{T-6}}$.

In this model, the cloud's boundary is determined based on the supersaturation with respect to water $(\mathrm{S})$ being equal to zero. This means that the positive amount of $\mathrm{S}$ shows the existence of the cloud, saturation with respect to water, 
(a) "S " no-seeding (CTL=7km)

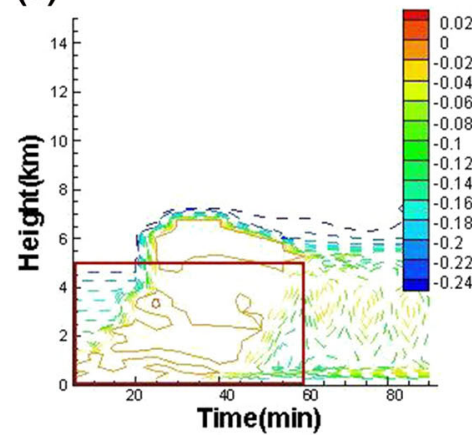

(b) "S" no-seeding (CTL=10.5 km)

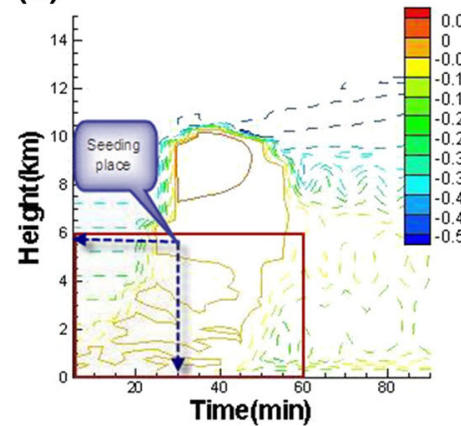

(a) "S" no-seeding (CTL=7km)

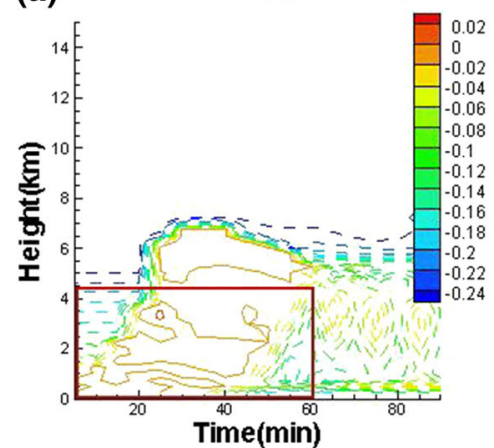

(b) "S" no-seeding (CTL=10.5 km)

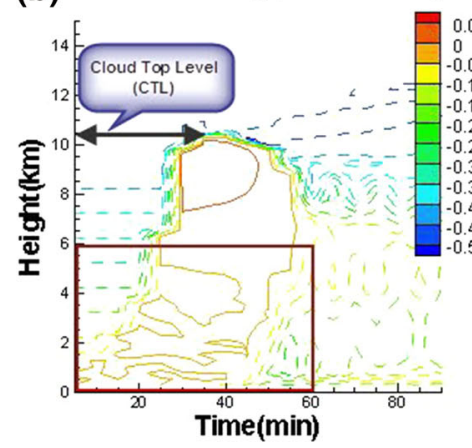

(a) "S" point se eding using Agi

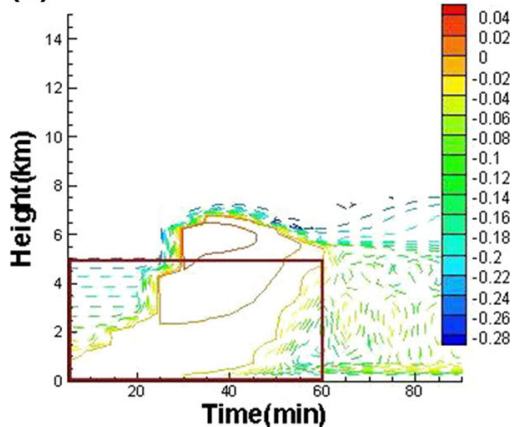

(b)

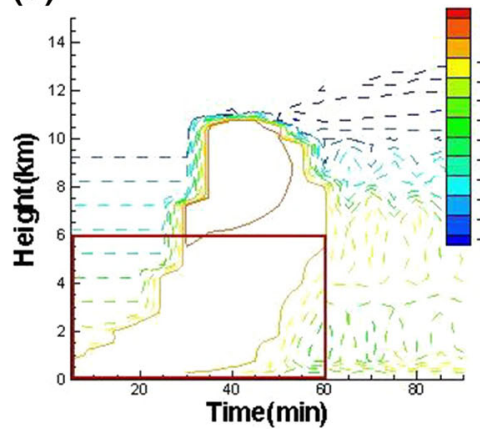

(a)

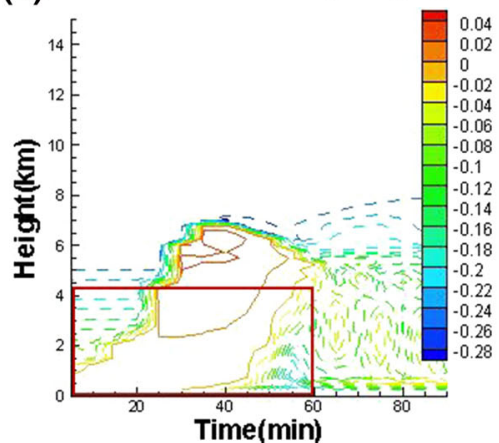

(b) "S "horizontal seeding using Agi

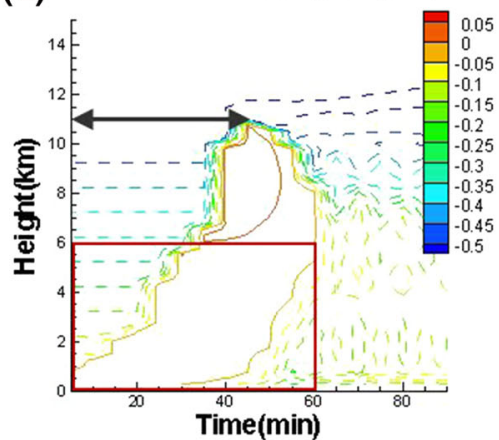

(a) "S " point seeding using LCO2

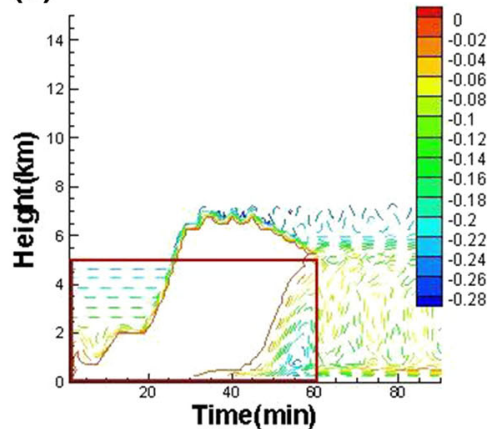

(b) "s " point see ding using LCO2

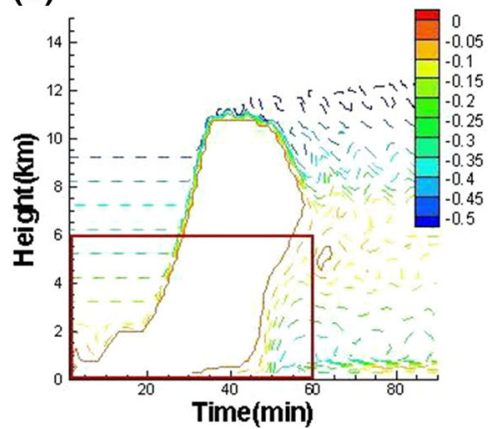

(a) "S "horizontal seeding using LCO2

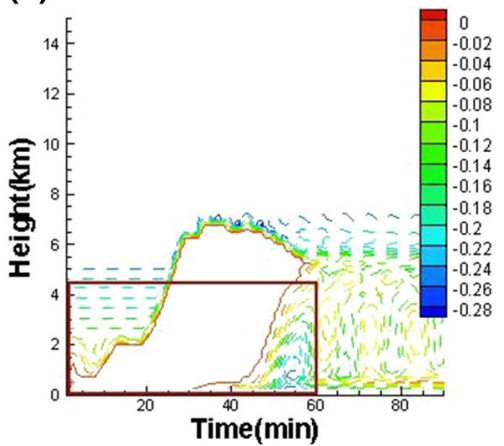

(b) "S "horizontal seeding using LCO2

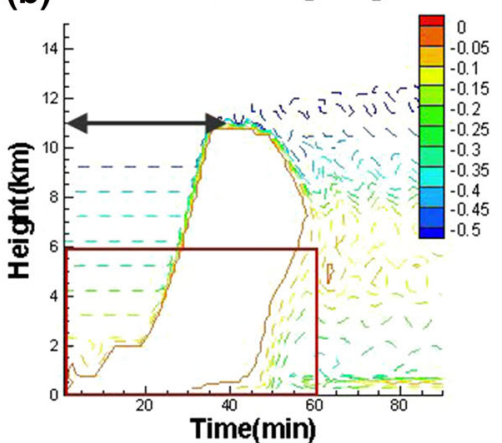

Fig. 5 Height versus time for supersaturation with respect to water (S)

condensation, and rainfall probability. The negative amount of $\mathrm{S}$ indicates the evaporation and cloud disappearance. The effective factor on the cloud vertical extension is the environmental lapse rate above the cloud base. When the lapse rate becomes more than the saturated lapse rate, conditions for the saturated air become unstable, creating upward motions. When the saturated air reaches a stable air layer, the cloud top extends horizontally. In this model, depending on the upper air data, the top of the cloud can go upward until it arrives at a level at which ice crystals can be formed, and consequently, a cumulonimbus cloud can be created. Figure 5 shows the variations of $S$ 
(a) "Si"no-seeding (CTL=7km)

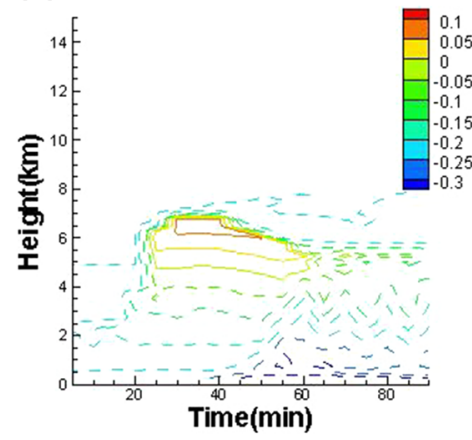

(b) " $\mathrm{Si}$ "no-seeding (CTL=10.5 km)

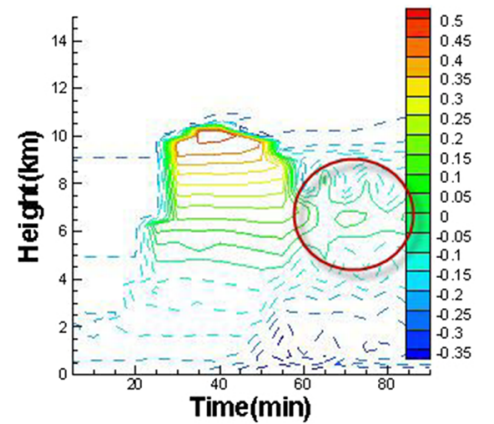

(a) "Si" no-seeding (CTL=7km)

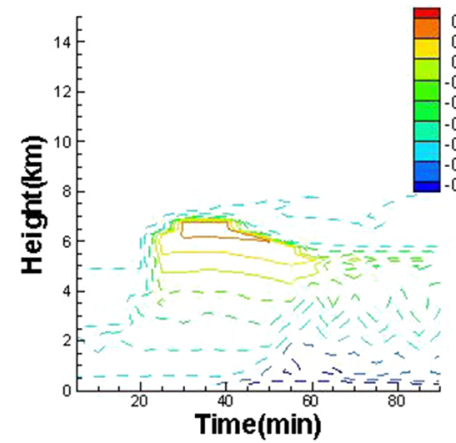

(b) " $\mathrm{Si}$ " no-seeding (CTL=10.5 km)

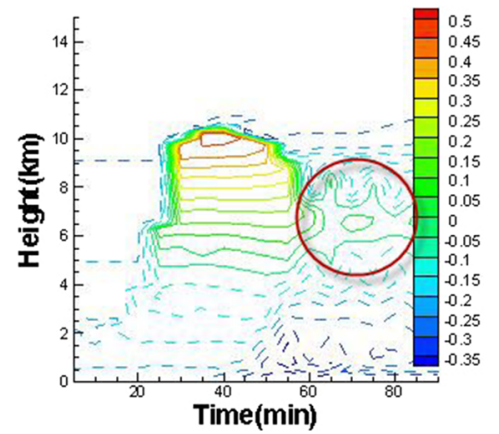

(a) "Si" horizontal se eding using Agi

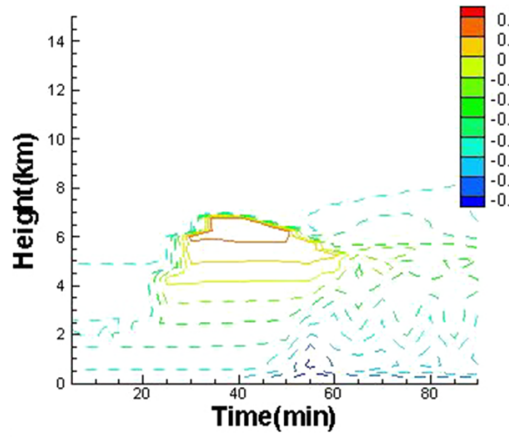

(b)

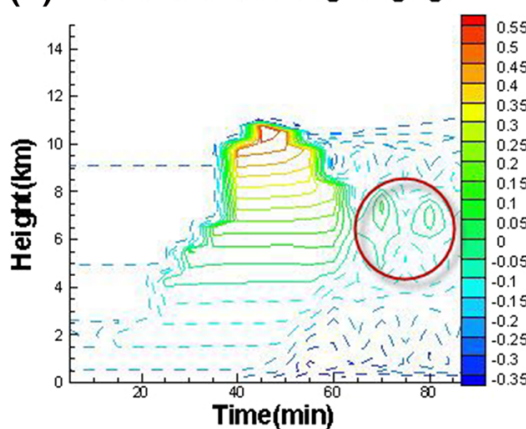

(a) "Si " point seeding using Agi

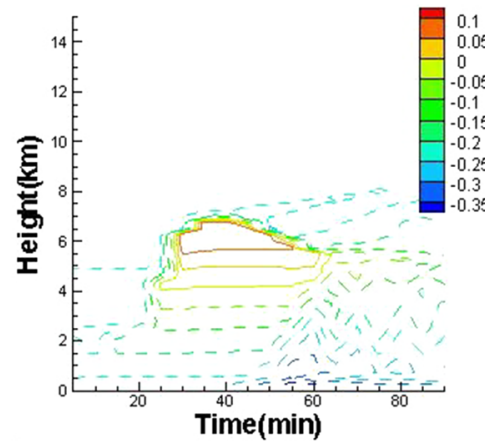

(b) "Si" point see ding using Agi

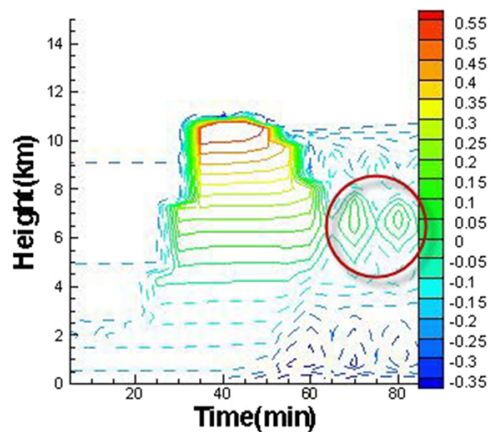

(a) "Si "horizontal seeding using LCO2

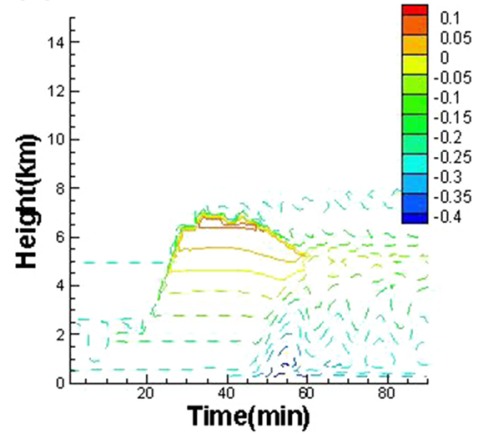

(b) " $\mathrm{Si}$ " horizontal seeding using LCO2

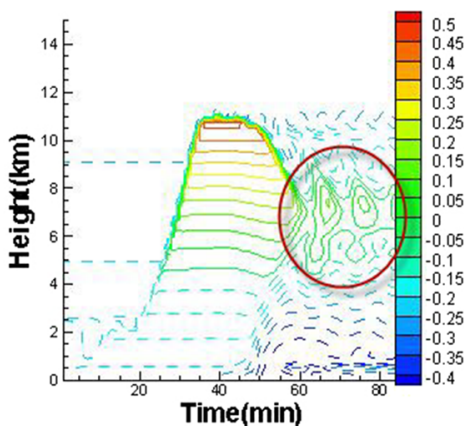

(a) " $\mathrm{Si}$ " point seeding using $\mathrm{LCO} 2$

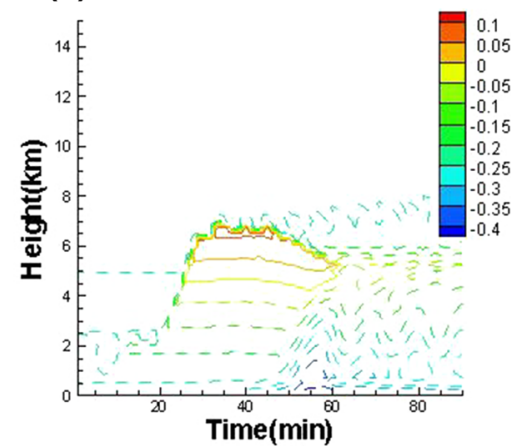

(b) " $\mathrm{Si}$ " point see ding using $\mathrm{LCO} 2$

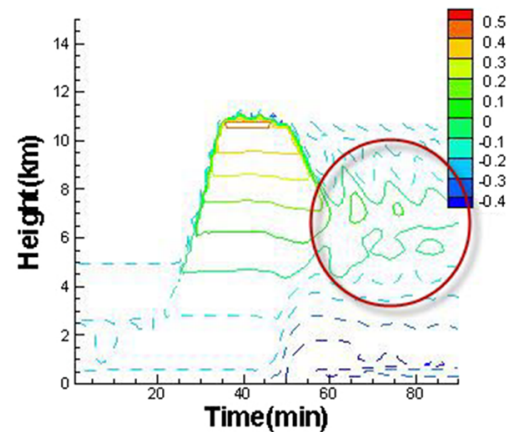

Fig. 6 Height versus time for supersaturation with respect to ice (Si)

versus height and time for the no-seeding, point seeding, and horizontal seeding cases. As they are indicated in the figure by red squares, the height and time continuity of the cloud boundary in the seeding cases are more than those in the no-seeding case.
Section B: Vertical velocity $(w)$ in the cloud

Figure 7 shows variations of vertical velocity $(w)$ versus height and time for the no-seeding case, for both the point and horizontal seeding methods using $\mathrm{AgI}$ and $\mathrm{LCO}_{2}$ for 
(a) "w" no-seeding (CTL=7 km)

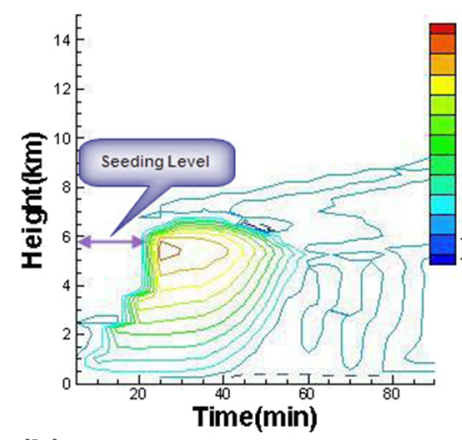

(b) " $w$ " no-seeding (CTL=10.5km)

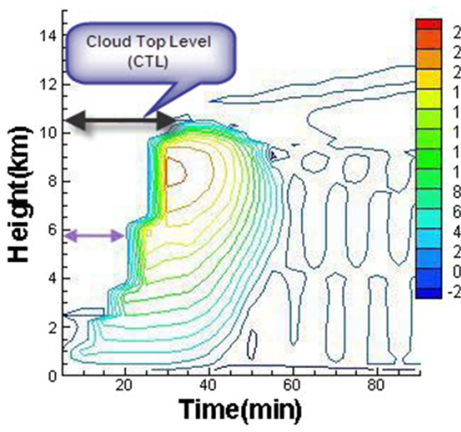

(a) "w" no-seeding (CTL=7km)

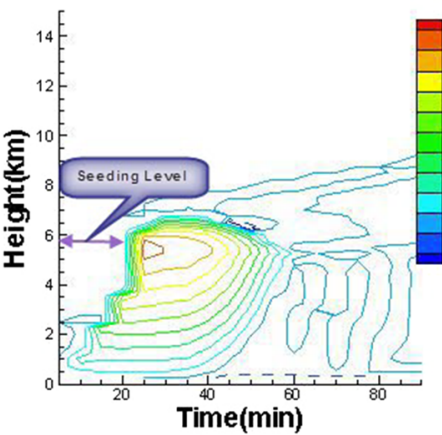

(b) " $w$ " no-seeding (CTL=10.5km)

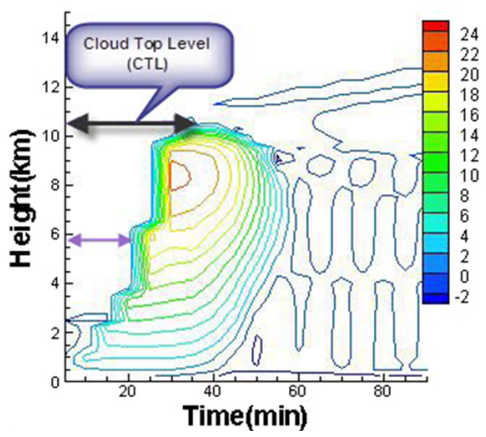

(a) "w" point seeding using AgI

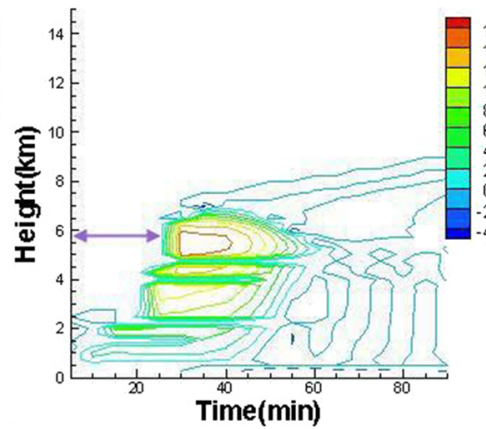

(b) " $w$ " point seeding using AgI

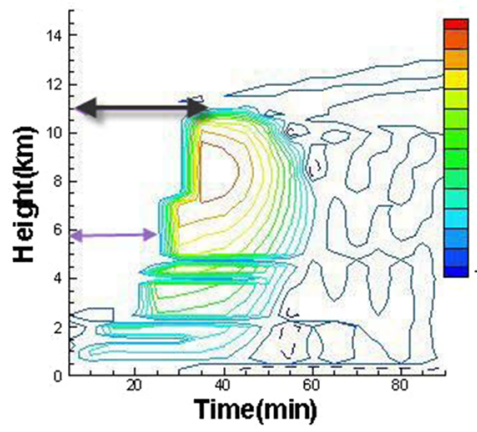

(a) "w" horizontal seeding using Agi

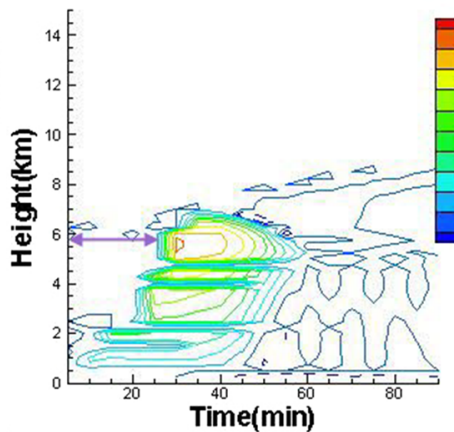

(b) " $w$ " horizontal see ding using Agi

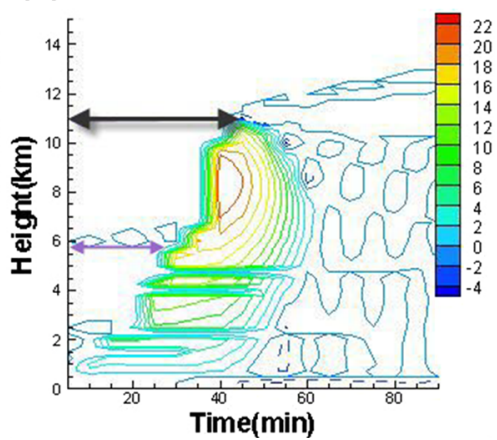

(a) " $w$ " point seeding using LCO2

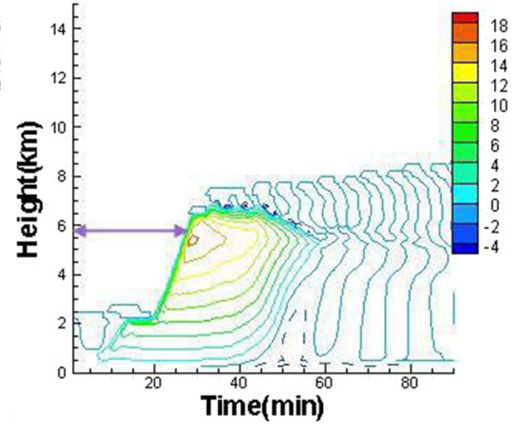

(b) " $w$ " point seeding using LCO2

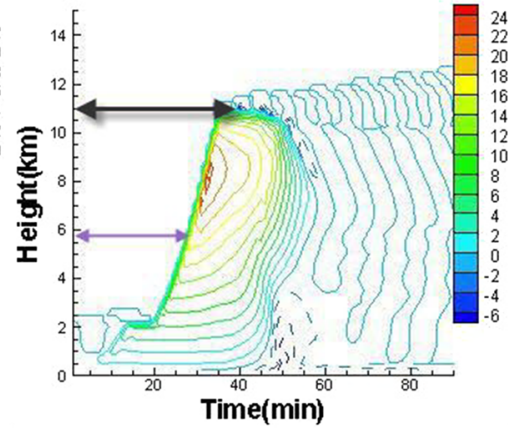

(a) " $w$ " horizontal seeding using LCO2

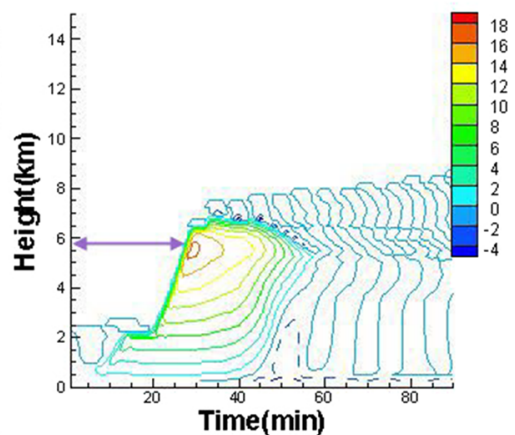

(b) " w " horizontal seeding using LCO2

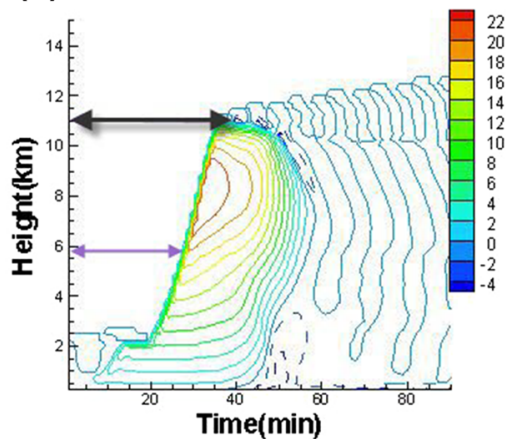

Fig. 7 Height versus time for vertical velocity "w"

clouds with CTLs of 7 and $10.5 \mathrm{~km}$. As this figure shows, the stages of the cloud life cycle namely, the developing, mature, and dissipation stages, according to the definition of Ogura and Takahashi (1971) and Gharaylou (2010), are recognized here. In the developing stage, since the air parcel has the maximum kinetic energy obtained by the integration of the positive buoyancy, the upward motion induced by the kinetic energy is dominated in the entire cloud. The cloud stage shifts from the developing stage to the mature stage when the upward motion induced by the kinetic energy is disappeared from the entire cloud regions; hence, the downward motions begin. In the dissipation 
(a) "TT" no-seeding (CTL=7 km)

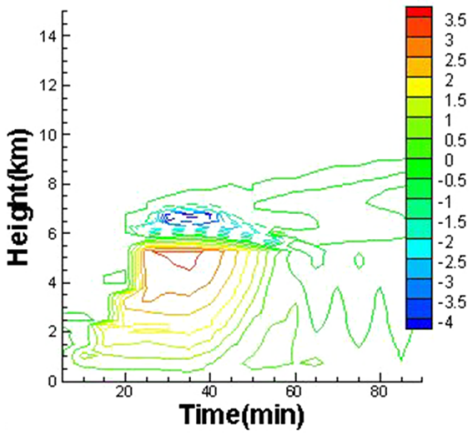

(b) " $T "$ no-seeding (CTL=10.5km)

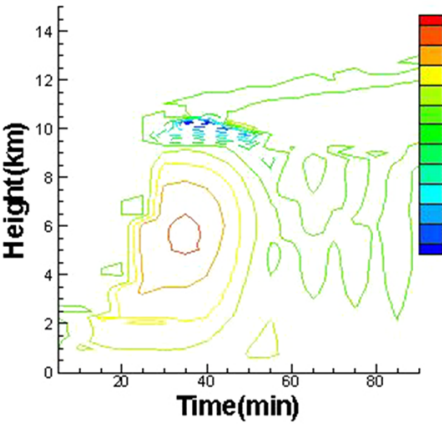

(a) " $T$ " no-seeding (CTL=7km)

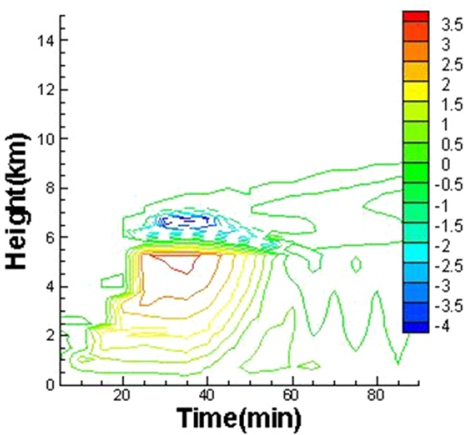

(b) "TT" no-seeding (CTL $=10.5 \mathrm{~km})$

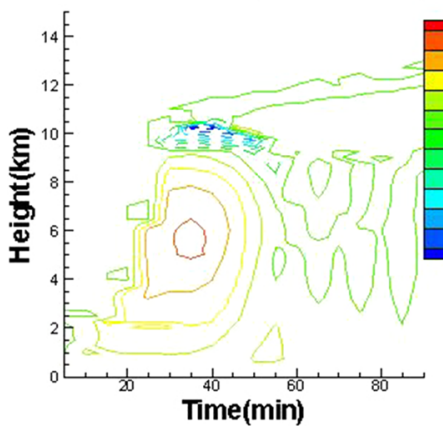

(a) "TT" point se eding using Agi

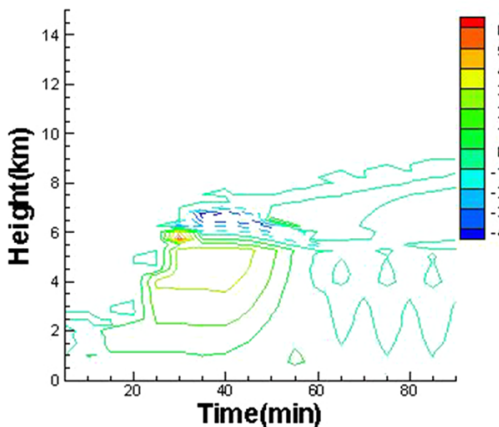

(b) " $T$ " point seeding using Agi

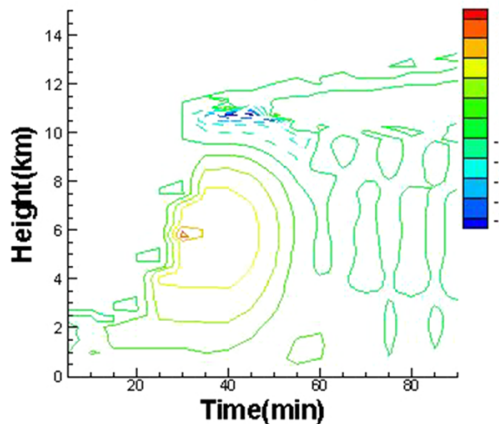

(a) " $\pi$ " horizontal se eding using Agi

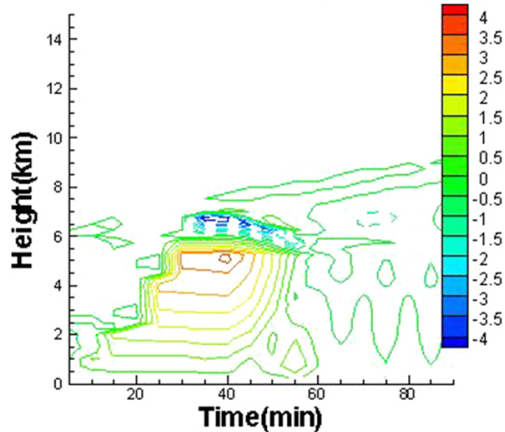

(b) " $T$ " horizontal seeding using Agi

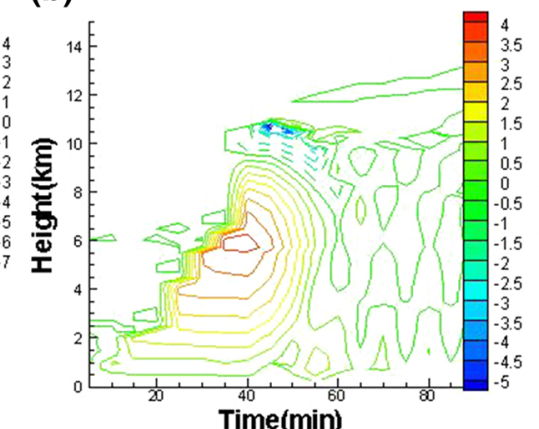

(a) " $\pi$ " point seeding using $\mathrm{LCO} 2$

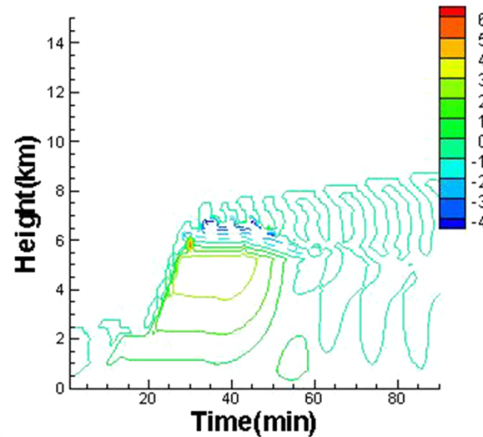

(b) "TT" point seeding using LCO2

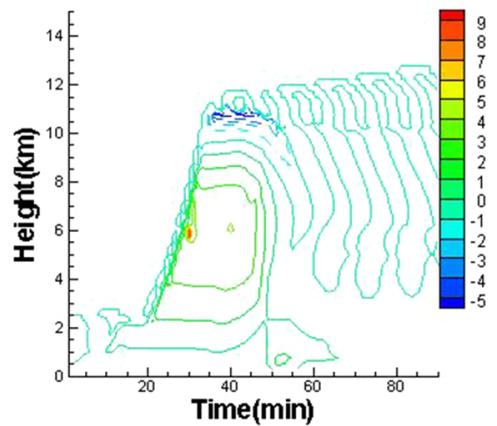

(a) " $T$ " horizontal see ding using LCO2

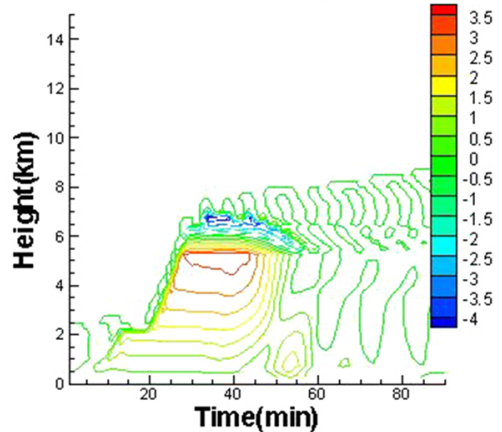

(b) " $\pi$ " horizontal seeding using LCO2

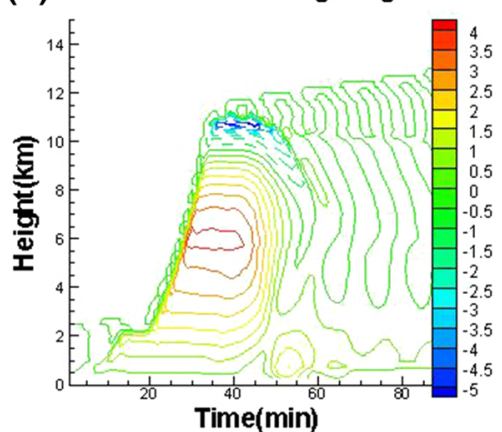

Fig. 8 Height versus time for temperature difference (TT)

stage, the downward motions (dashed lines in Fig. 7) are the dominated motions in the cloud. Moreover, the clouds are seeded at the early mature stage (after $30 \mathrm{~min}$ from beginning of the cloud life cycle) and at a height of about $5.75 \mathrm{~km}$ above the ground surface having $-10^{\circ} \mathrm{C}$ temperatures. In the horizontal seeding case, the seeding duration is $30 \mathrm{~min}$.

As Fig. 7 shows, in the $\mathrm{LCO}_{2}$ seeding, the vertical velocity reaches its maximum at the end of the developing stage with a steep slope and the downward motions become 
(a) Graupel mixing ratio ( $g / \mathrm{kg})$

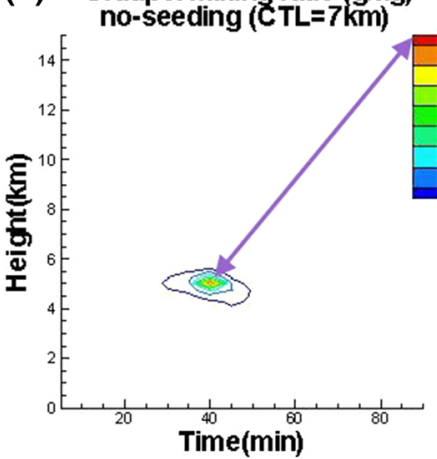

(b) Graupel mixing ratio $(g / \mathrm{kg})$

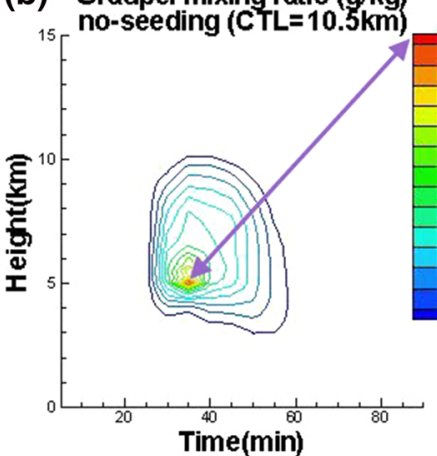

(a) Graupel mixing ratio $(g / \mathrm{kg})$

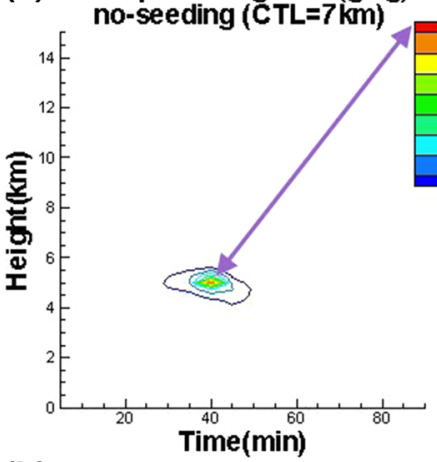

(b) Graupel mixing ratio $(\mathrm{g} / \mathrm{kg})$

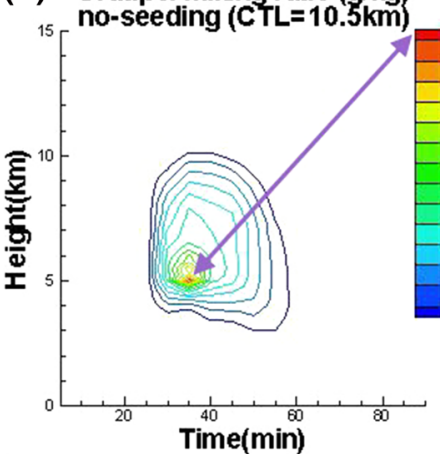

(a) Graupel mixing ratio ( $g / \mathrm{kg})$ point seeding using Agl

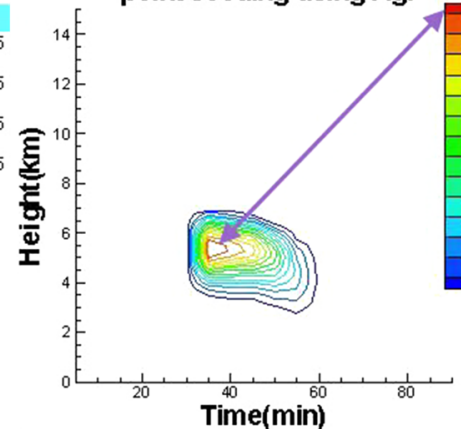

(b) Graupel mixing ratio $(g / \mathrm{kg})$

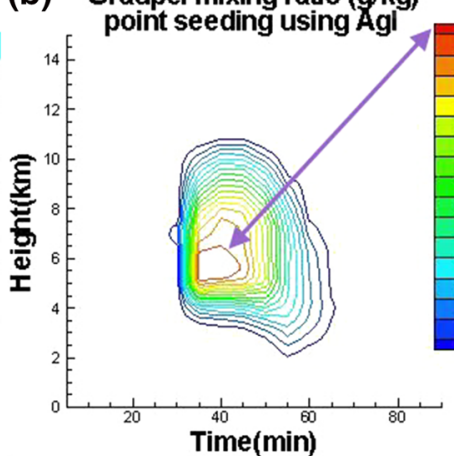

(a) Graupel mixing ratio $(\mathrm{g} / \mathrm{kg})$

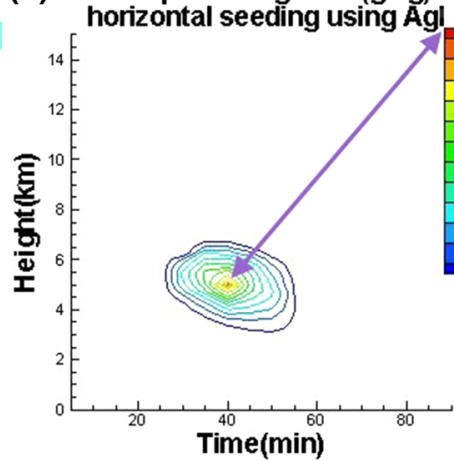

(b) Graupel mixing ratio $(\mathrm{g} / \mathrm{kg})$

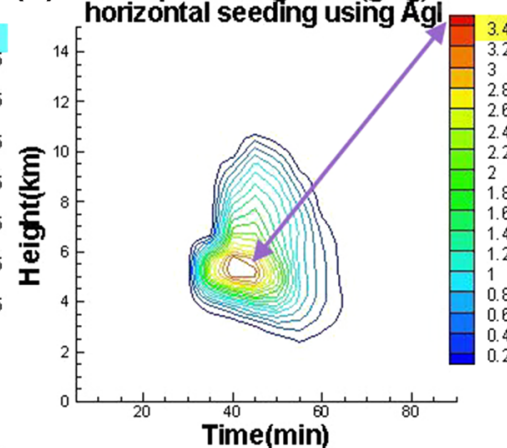

(a) Graupel mixing ratio ( $g / \mathrm{kg}$ ) point seeding using $\mathrm{LCO} 2$

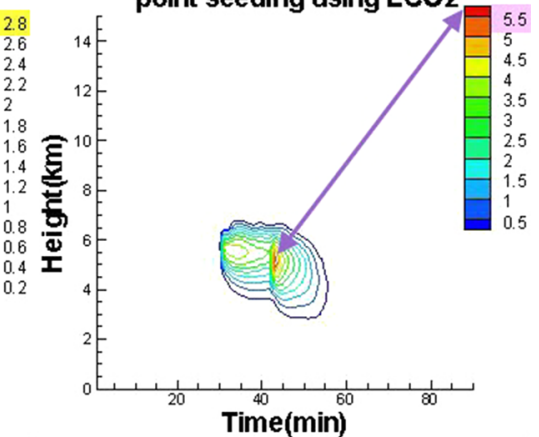

(b) Graupel mixing ratio $(\mathrm{g} / \mathrm{kg})$

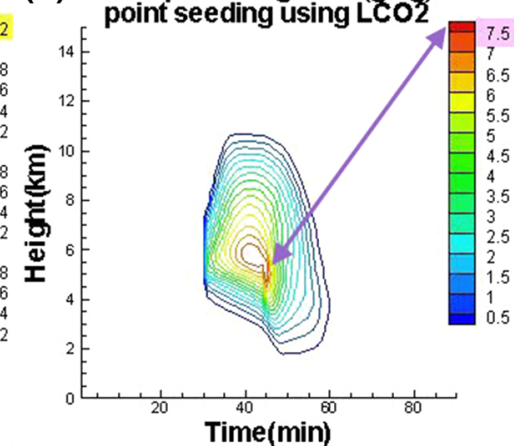

(a) Graupel mixing ratio $(g / \mathrm{kg})$

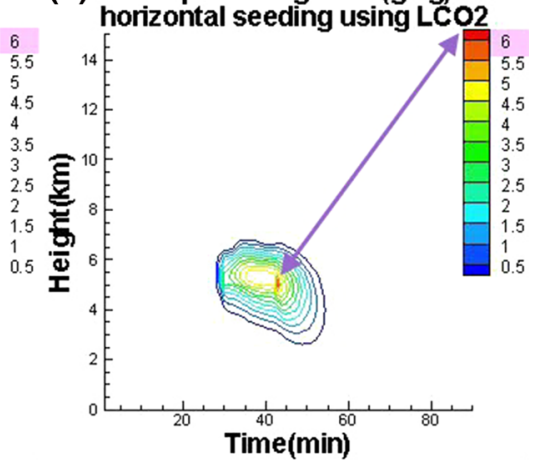

(a) Graupel mixing ratio $(g / \mathrm{kg})$ horizontal seeding using LCO2

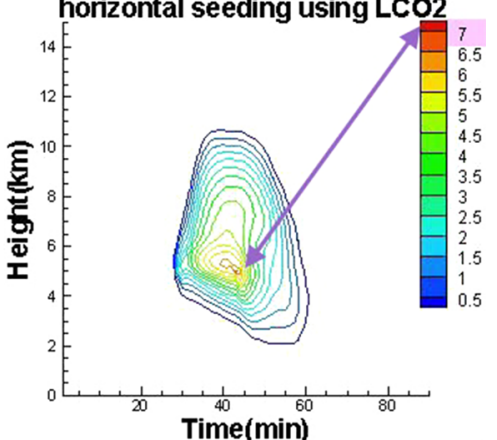

Fig. 9 Graupel mixing ratio

stronger with a significant increase of temporal distribution in the dissipating stage. In the AgI seeding cases, at each specific moment of the cloud life cycle, as the cloud altitude is increased, the vertical velocity is increased and decreased stochastically. The reason may refer to the fact that, in the case of AgI seeding, the positive amount of supersaturation with respect to water $(\mathrm{S})$ is increased which affects the ice formation process commencement. Successive increase and decrease of vertical velocity in these cases indicate exothermic and endothermic processes due 
Fig. 10 Height versus time for cloud water mixing ratio before seeding

\section{(a) Cloud water mixing ratio(g/kg)
no-seeding $(\mathrm{CTL}=7 \mathrm{~km})$}

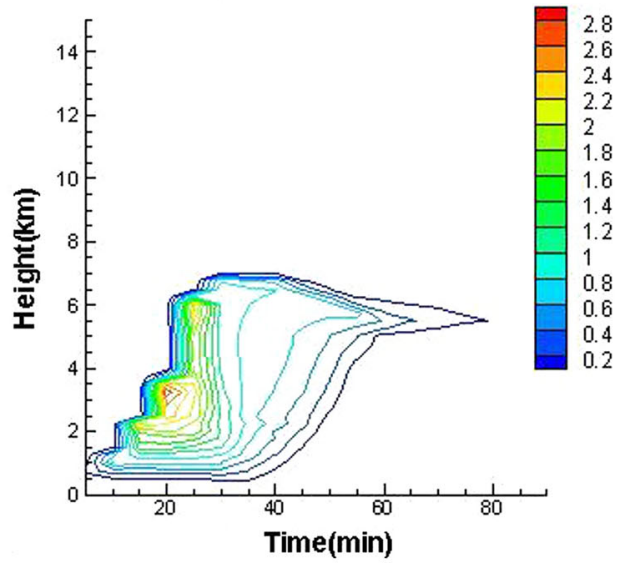

(b) Cloud water mixing ratio $(\mathrm{g} / \mathrm{kg})$ no-seeding $(C T L=10.5 \mathrm{~km})$

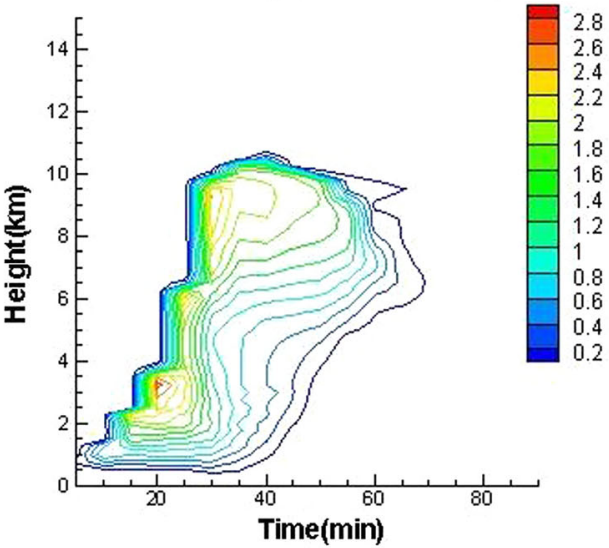

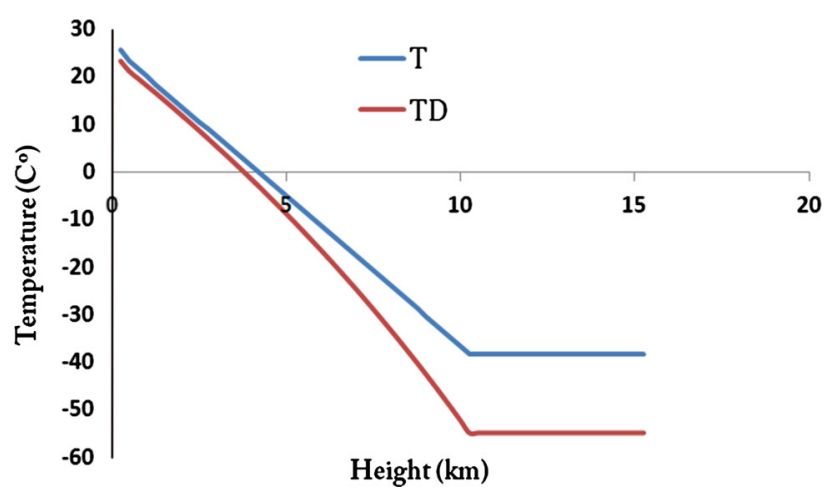

Fig. 11 Two sounding data before seeding: potential temperature (T) and dew point temperature (TD)

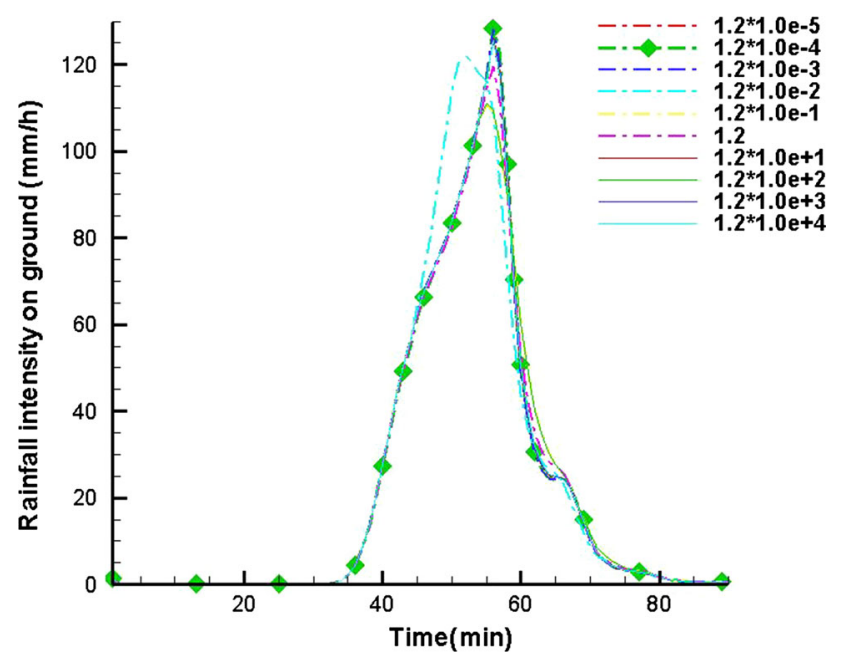

Fig. 12 Rainfall intensity on ground versus time for different amount of AgI mixing ratios $(\mathrm{g} / \mathrm{g})$

to different sorts of water phase changes. In other words, the lapse rate exceeds the saturation lapse rate; hence, conditions for the saturated air become unstable, creating upward motions. When the saturated air reaches a stable air layer, the cloud top extends horizontally. Near the cloud top, the cloud water is evaporated due to entrainment of the cold dry air into the cloud. Moreover, in this region (which is the region of the evaporation cooling), temperature difference between the environment and cloud (TT) is negative (dashed lines in Fig. 8) and the amount of water within the cloud decreases gradually and the downdraft motions begin (dashed lines in Fig. 7). As shown in this figure, temporal extension and maximum amount of downward motions in the cloud due to the $\mathrm{LCO}_{2}$ seeding are more than those in the case of AgI seeding. The seeding level and CTL are indicated in this figure.

Section C: $\mathrm{LCO}_{2}$ amount for seeding

According to Fukuta (1996), the rate of $\mathrm{LCO}_{2}$ seeding can be calculated by considering the mass of the existing ice crystals in the cloud $\left(m_{\mathrm{C}}=10^{-5} \mathrm{~g}\right)$, number of ice crystals generated by $\mathrm{LCO}_{2}\left(n=10^{13} \mathrm{~g}^{-1}\right)$, liquid water content $\left(w_{l}=0.5 \frac{\mathrm{g}}{\mathrm{m}^{3}}\right)$, and the mass of $\mathrm{LCO}_{2}$ for volume $V\left(\mathrm{~m}^{3}\right)$ of cloud or moist weather, therefore,

$m_{\mathrm{LCO}_{2}}=\frac{w_{l} V}{n m_{\mathrm{C}}}$.

For this model, the seeding agent mixing ratio $\left(X_{\mathrm{LCO}_{2}}\right)$ is used for the cloud seeding and this ratio can be obtained by,

$$
\begin{aligned}
X_{\mathrm{LCO}_{2}}(j) & =\frac{m_{\mathrm{LCO}_{2}}}{m_{\text {air }}}=\frac{0.5 \times 10^{-3} \frac{\mathrm{kg}}{\mathrm{m}^{3}} \times V}{10^{13} \mathrm{gr}^{-1} \times 10^{-5} \mathrm{gr} \times \rho_{\text {air }} \frac{\mathrm{kg}}{\mathrm{m}^{3}} \times V} \\
& =\frac{5 \times 10^{-12}}{\rho_{\text {air }}(j)} \frac{\mathrm{g}}{\mathrm{g}},
\end{aligned}
$$

where $m_{\text {air }}$ and $\rho_{\text {air }}$ denote mass and density of the air column at the injection height $(5.75 \mathrm{~km})$, respectively (Fukuta 1996). 
Section D: Microphysical processes

In Eq. 4, $P$ indicates microphysical processes which are, condensation of cloud water $\left(P_{\mathrm{COND}}\right)$, homogenous ice nucleation $\left(P_{\mathrm{NUH}}\right)$, production of cloud ice using ice nuclei $\left(P_{\mathrm{NUF}}\right.$ ), freezing of cloud water (for $\Delta T \leq 40$ ) to form cloud ice $\left(P_{\mathrm{NUA}}\right)$, evaporation of cloud water $\left(P_{\mathrm{CLEVP}}\right)$, rain water $\left(P_{\mathrm{REVP}}\right)$, and cloud ice $\left(P_{\mathrm{IEVP}}\right)$, sublimation of snow $\left(P_{\mathrm{SSUB}}\right)$, and of graupel $\left(P_{\mathrm{GSUB}}\right)$, depositional growth of snow $\left(P_{\mathrm{SDEP}}\right)$ and of cloud ice $\left(P_{\mathrm{IDEP}}\right)$, accretion of cloud water by snow $\left(P_{\mathrm{SACW}}\right)$ and by graupel $\left(P_{\mathrm{GACW}}\right)$, melting of snow $\left(P_{\mathrm{SMLT}}\right)$, and of graupel $\left(P_{\mathrm{GMLT}}\right)$, and of cloud ice $\left(P_{\mathrm{IMLT}}\right)$, Bergeron process transformation of cloud water to form snow $\left(P_{\mathrm{SFW}}\right)$, probabilistic freezing of rain to form graupel $\left(P_{\mathrm{GFR}}\right)$, accretion of rainwater by graupel $\left(P_{\mathrm{GACR}}\right)$, accretion of rain and snow by cloud ice $\left(P_{\text {IACRS }}\right)$, accretion of rain and snow by snow $\left(P_{\mathrm{SACRS}}\right)$, and accretion of rain and graupel by snow $\left(P_{\mathrm{SACRG}}\right)$ and by cloud ice $\left(P_{\mathrm{IACRG}}\right)$. The energy equation also takes into account three more terms associated with the seeding processes including transformation of rainwater to precipitating ice $\left(P_{\mathrm{ISR}}\right)$, transformation of cloud water to cloud ice due to the contact nucleation $\left(P_{\mathrm{CSWC}}\right)$, and depositional nucleation due the Bergeron-Findisen process $\left(P_{\mathrm{CSWD}}\right)$ (Hsie et al. 1980; Guo et al. 2006; Javanmard and Jamali 2004).

\section{Section E: Figures}

In Figs. 5, 6, 7, and 8 the dashed and solid lines indicate the appropriate negative and positive quantities, respectively (Figs. 9, 10, 11, 12).

\section{References}

Braham RR Jr (1986) Precipitation enhancement-A scientific challenge. Meteor Monogr Am Meteor Soc 21(43):1-6

Bruintjes RT (1999) A review of cloud seeding experiments to enhance precipitation and some new prospects. Bull Am Meteorol Soc 5:805-820

Chen CS, Orville HD (1977) The effects of carbon black dust on cumulus scale convection. J Appl Meteorol 16:401-412

Chen S, Sun W (2002) A one-dimensional time dependent cloud model. J Meteorol Soc Jpn 1:99-118

Chen B, Xiao H (2010) Silver iodide seeding impact on microphysics and dynamics of convective clouds in the high plains. Atmos Res 96:186-207

Conrad GK (ed) (2006) Guidelines for cloud seeding to augment precipitation. Manual and reports on engineering practice no. 81, 2nd edn. ASCE, Reston, VA, pp 71-74

Cotton WR, Tripoli GJ, Rauber RM, Mulvihill EA (1986) Numerical simulation of the effects of varying ice crystal nucleation rates and aggregation processes on orographic snowfall. J Clim Appl Meteor 25:1658-1680

English M, Marwitz JD (1981) A comparison of $\mathrm{AgI}$ and $\mathrm{CO}_{2}$ seeding effects in Alberta cumulus clouds. J Appl Meteorl 20(5):483-495
Franklin CN, Holland GJ, May PT (2005) Sensitivity of tropical cyclone rainbands to ice-phase microphysics. Mon Weather Rev 133:2473-2493

Fukuta N (1996) Project mountain valley sunshine-progress in science and technology. J Appl Meteorol 35:1483-1493

Gao W, Zhao F, Hu Z, Feng XA (2011) Two-moment bulk microphysics scheme coupled with a mesoscale model (WRF) model description and first results. Adv Atmos Sci 28(5):1184-1200

Garstang M, Bruintjes R, Serafin R, Orvill H, Boe B, Cotton W, Warburton J (2005) Weather modification: finding common ground. Bull Am Meteorol Soc 86:647-655

Garvey DM (1975) Testing of cloud seeding materials at the cloud simulation and aerosol laboratory, 1971-1973. J Appl Meteorl $14: 883-890$

Gharaylou M (2010) Parameterization of cumulus convective using a one-dimensional time-dependent tilting cloud model and implementation in a mesoscale model. Ph.D. dissertation, University of Tehran, Iran

Gharaylou M, Zawar-Reza P, Farahani MM (2009) A one-dimensional explicit time-dependent cloud model (ETM): description and validation with a three-dimensional cloud resolving model. Atmos Res 92(4):394-401

Golestani S (2011) Investigation on atmospheric physics parameters using satellite TRMM-TMI data over Iran. M.S. dissertation, University of Zanjan, Iran

Griffith DA, Solak CME (2006) The potential use of winter cloud seeding programs to augment the flow of the Colorado River. Prepared for Upper Colorado River commission. North American Weather Consultants, Inc, Sandy, pp 1-50

Guo X, Zheng G, Jin D (2006) A numerical comparison study of cloud seeding by silver iodide and liquid carbon dioxide. J Atmos Res 79:183-226

Heymsfield AJ (1982) A comparative study of the rates of development of potential graupel and hail embryos in high plains storms. J Atmos Sci 39:2867-2897

Hsie EY, Farley RD, Orville HD (1980) Numerical simulation of icephase convective cloud seeding. J Appl Meteorol 19:950-977

Javanmard S (1999) Numerical modeling for low level horizontal penetration seeding super-cooled cloud with liquid carbon dioxide. Ph.D. dissertation, University of Kyushu, Japan

Javanmard S, Jamali JB (2004) Improvement of microphysical and dynamical parameterization of Ogura and Takahashi's numerical thunderstorm model. Iran J Sci Technol 28:595-604

Javanmard S, Karimpirhayati M (2012) AgI cloud seeding modeling for hail suppression of cold clouds. J Geogr Geol 4(2):81-93

Javanmard S, Mohammad-Hosseinzadeh F (2012) A numerical analysis of homogeneous cloud seeding agent based on sensitivity tests in different conditions. J Basic Appl Sci Res 2(7):7328-7342

Javanmard S, Jamali JB, Rajaei VM (2008) Numerical study of microphysical parameterization in one-dimensional thunderstorm cloud model. Iranian Annual Physics Conference, Kashan

Johnson DE, Wang PK, Straka JM (1993) Numerical simulations of the 2 August 1981 CCOPE supercell storm with and without ice microphysics. J Appl Meteorol 32(3):745-759

Johnson DE, Wang PK, Straka JM (1994) A study of microphysical process in the 2 August 1981 CCOPE supercell storm. Atmos Res 33:93-123

Karimpirhayati M (2010) Investigation on cloud seeding effect on natural precipitation process using cloud physics numerical models. M.S. dissertation, Faculty of science, Zanjan University, Iran

Khain AP (2009) Notes on state-of-the art investigations of aerosol effects on precipitation: a critical review. Environ Res Lett 4(1):015004. doi:10.1088/1748-9326/4/1/015004 
Khain A, Ovtchinnikov M, Pinsky M, Pokrovsky A, Krugliak H (2000) Notes on the state-of-the-art numerical modeling of cloud microphysics. Atmos Res 55(4):159-224

Khain A, Rosenfeld D, Pokrovsky A, Blahak U, Ryzhkov A (2011) The role of $\mathrm{CCN}$ in precipitation and hail in a mid-latitude storm as seen in simulations using a spectral (bin) microphysics model in a 2D dynamic frame. Atmos Res 99:129-146

Krauss TW (1999) Hail suppression. In: Invited lecture at 7th WMO scientific conference on weather modification, Chiang Mai, Thailand, 17-22 February

Lee SS, Donner LJ (2011) Effects of cloud parameterization on radiation and precipitation: a comparison between singlemoment microphysics and double-moment microphysics. Terr Atmos Ocean Sci 22(4):403-420

Levin Z, Cotton WR (eds) (2009) Aerosol pollution impact on precipitation: a scientific review. Springer, Berlin, p 386

Lim K-SS, Hong S-Y (2010) Development of an effective doublemoment cloud microphysics scheme with prognostic cloud condensation nuclei $(\mathrm{CCN})$ for weather and climate models. Mon Weather Rev 138:1587-1610

Lin YL, Farley HD, Orville HD (1983) Bulk parameterization of snow field in a cloud model. J Clim Appl Meteorol 23:1065-1092

Morin E, Goodrich DC, Maddox RA, Gao X, Gupta HV, Sorooshian $S$ (2006) Spatial patterns in thunderstorm rainfall events and their coupling with watershed hydrological response. Adv Water Resour 29:843-860

Morrison H, Curry JA, Khvorostyanov VI (2005) A new doublemoment microphysics parameterization for application in cloud and climate models, part I: description. J Atmos Sci 62:1665-1677

Najafi M, Mohammad-Hosseinzadeh F (2013) Numerical simulation of deep convective cloud seeding using liquid carbon dioxide. Int J Environ Sci Technol 10:665-667

Ogura Y, Takahashi T (1971) Numerical simulation of the life cycle of a thunderstorm cell. Mon Weather Rev 99(12):895-911

Orville HD (1996) A review of cloud modeling in weather modification. Bull Am Meteorol Soc 77:1535-1555

Orville HD, Farley RD, Hirsch JH (1984) Some surprising results from simulated seeding of stratiform-type clouds. J Clim Appl Meteorol 23:1585-1600

Orville HD, Hirsch JH, Farley RD (1987) Further results on numerical cloud seeding simulations of stratiform-type clouds. J Weather Modif 19:57-61

Pruppacher HR, Klett JD (1997) Microphysics of clouds and precipitation, 2nd edn. Oxford Press, Oxford, pp 548-549

Reisner J, Rasmussen RM, Bruintjes RT (1998) Explicit forecasting of super-cooled liquid water in winter storms using the MM5 forecast model. Quart J R Meteorol Soc 124:1071-1107

Rogers RR, Yau MK (1989) A short course in cloud physics, 3rd edn. Butterworth-Heinemann, Woburn, MA, pp 190
Rosenfeld R, Woodley WL (1989) Effects of cloud seeding in West Texas. J Appl Meteorol 28:1050-1080

Rosenfeld D, Lohmann U, Raga GB, O’Dowd CD, Kulmala M, Fuzzi S, Reissell A, Andreae MO (2008) Flood or drought: how do aerosols affect precipitation? Science 321:1309-1313

Rui C, Rucong YU, Yunfei FU, Youping XU (2010) Impact of cloud microphysical processes on the simulation of typhoon rananim near shore. Part I: cloud structure and precipitation features. Acta Meteorol Sinica 4:441-455

Schlesinger RE, Hubbard SA, Wang PK (2006) A three-dimensional cloud modeling study on the dynamical and microphysical variability of thunderstorms in different climate regimes. In: AMS (American Meteorological Society), 12th atmospheric radiation/cloud physics, Madison, WI, USA, 10-14 July

Seto J, Tomine K, Wakimizu K, Nishhiyama K (2011) Artificial cloud seeding using liquid carbon dioxide: comparisons' of experimental data and numerical analyses. $J$ Appl Meteorol 50:1417-1431

Silverman BA (2001) A critical assessment of glaciogenic seeding of convective clouds for rain enhancement. Bull Am Meteorol Soc 82:903-924

Tao W-K, Simpson J (1993) The Goddard cumulus ensemble model, part 1: model description. Terr Atmos Oceanic Sci 4:35-72

Teller A, Levin Z (2005) The effects of aerosols on precipitation and dimensions of subtropical clouds: a sensitivity study using a numerical cloud model. Atmos Chem Phys Discus 5:7211-7245

Teller A, Levin Z (2006) The effects of aerosols on precipitation and dimensions of subtropical clouds: a sensitivity study using a numerical cloud model. Atmos Chem Phys 6:67-80

Wakimizu K, Nishiyama K, Suzuki Y, Tomine K, Yamazaki M, Isimaru A, Ozaki M, Itano T, Naito G, Fukuta N (2002) A Lowlevel penetration seeding experiment of liquid carbon dioxide in a convective cloud. J Hydrol Process 16:2239-2253

Woodley WL, Jordan J, Simpson J, Biondini R, Flueck JA, Barnston A (1982) Rainfall results of the Florida area cumulus experiment, 1970-1976. J Appl Meteorol 21:139-164

Xiao H, Zhai W, Chen Z, He Y, Jin D (2005) A modeling method of cloud seeding for rain enhancement. Current trends in high performance computing and its applications. Springer, Berlin, pp 539-543

Young KC (1974) The role of contact nucleation in ice phase initiation in clouds. J Atmos Sci 31:768-776

Zhao Z, Lei H-C (2010) Numerical simulation of seeding extra-area effects of precipitation using a three-dimensional mesoscale model. Atmos Ocean Sci 3(1):19-24

Zipori A, Rosenfeld D, Shpund J, Steinberg D, Erel Y (2012) Targeting and impacts of AgI cloud seeding based on rain chemical composition and cloud top phase characterization. Atmos Res 114(115):119-130 